\title{
EL ANÁLISIS DE LAS RELACIONES COMERCIALES DE TAIWÁN CON LOS PAÍSES DEL TRIANGULO NORTE DE CENTROAMERICA
}

\author{
Jeison Eduardo Gomes Escobar** \\ María Auxiliadora López *
}

DOI: 10.5377/eya.v10i1.9046

Recibido: 6/08/2019 Aceptado:12/12/2019

\section{RESUMEN}

Este trabajo de investigación presenta un amplio panorama sobre las relaciones comerciales de Honduras, El Salvador y Guatemala (Triángulo Norte de Centroamérica) con la República de China (Taiwán), bajo la premisa del impacto económico y social que estas relaciones comerciales han producido en los habitantes de los países signatarios, a través de datos estadísticos de exportación e importación, así como analizando aspectos de carácter económico de Taiwán.

El comercio internacional ha tomado auge en todos los países alrededor del mundo en los últimos 30 años, principalmente por el incremento de los volúmenes del intercambio de los productos entre las naciones, la apertura comercial que han adoptado la gran mayoría de los países del hemisferio, y las tendencias de un sistema económico global orientado hacia una economía de mercado impulsada principalmente por el capitalismo. Estos factores incrementan las posibilidades de los países de tener acceso a aquellos bienes y servicios que no se producen en su territorio o que al producirlos tienen un alto costo en comparación con otros, aplicando así la división internacional del trabajo, la cual principalmente modela las características productivas que impulsaron el comercio en la antigüedad.

Palabras clave: comercio internacional, política comercial, economía, exportaciones, importaciones.

JEL: F13, F15, F53.

\footnotetext{
** Licenciado en Comercio Internacional, Universidad Nacional Autónoma de Honduras, UNAH.

* Profesora del Instituto de Investigaciones Económicas, IIES-FCEAC, Universidad Nacional Autónoma de Honduras, UNAH.
} 


\title{
THE ANALYSIS OF TRADE RELATIONS BETWEEN TAIWÁN WITH THE COUNTRIES OF THE NORTHERN TRIANGLE OF CENTRAL AMERICA
}

\author{
Jeison Eduardo Gomes Escobar
}

María Auxiliadora López

DOI: $10.5377 /$ eya.v10i1.9046

\begin{abstract}
This research paper pretends to present a broad view about the commercial relations of Honduras, El Salvador and Guatemala (Northern Triangle of Central America) along with the Chinese Republic (Taiwan) under the premise of economic and social impact that these commercial relations have crat in the inhabitants of the signatory countries through statistic data of exportation and importation as well as analyzing the economic nature of Taiwan.

The international trade has taken a rise in all the countries around the world in the last 30 years, mainly by the increase of volume of trade of products between countries of the hemisphere and the tendencies of a global economic system oriented towards a market economy boosted essentially by capitalism. These factors increase the possibilities of the countries to have access to those goods and services that are not created within their territory or that in the case of creating them have a high cost in contrast with others, this applying the international division of labor which primarily models the productive characteristics that prompted the trade in the past.
\end{abstract}

Thematic field: international trade, international economy, monetary economy.

Key words: international trade, trade policy, economy, exportations, importations.

JEL: F13, F15, F53. 


\section{INTRODUCCIÓN}

El comercio internacional ha desempeñado un rol trascendental en el desarrollo económico y social de la humanidad, este fenómeno toma importancia a medida que contribuye a generar riqueza económica en los países; riqueza que se mide a través del indicador macroeconómico de la producción de bienes y servicios que genera un país en un determinado periodo (PIB). Sobre la base de la defensa del comercio internacional se han creado diferentes herramientas $e$ instrumentos con la intención de facilitar e incrementar las relaciones comerciales internacionales, como los tratados de libre comercio, estos mecanismos se generan bajo la convicción de que la libertad del comercio como herramienta permite alcanzar un objetivo que se puede considerar universal: la mejora de las condiciones de vida y de trabajo de la población mundial que está íntimamente relacionada con la renta económica generada y su distribución. El auge de la interdependencia entre los países, impulsado por el fenómeno de la globalización y los avances en la tecnología, tienen un impacto directo en las relaciones comerciales internacionales, las cuales a través de factores que impulsan el libre mercado, los países logran una adecuada inserción en la comunidad internacional. Desde la creación de la Organización Mundial del Comercio (1995) máximo ente que regula el comercio internacional, las transacciones comerciales internacionales han aumentado significativamente, durante el período (1995 - 2016); por lo cual, el comercio ha sido un factor importante para ayudar a impulsar el crecimiento económico y sacar a millones de personas de la pobreza. (OMC, s. f.). Hasta finales de la década de 1990 e inicios del decenio del 2000 las corrientes comerciales mostraron un crecimiento significativo y después de la crisis económica de 2008 una caída moderada, en los últimos años se ha observado una gradual recuperación. Durante los últimos 20 años el comercio mundial de servicios comerciales ha sido menos volátil que el comercio de mercancías los servicios son más resistentes a las perturbaciones macroeconómicas mundiales que el sector primario de la economía.

Tabla 1. Exportaciones mundiales de servicios comerciales y mercancías periodo 1995 - 2015

\begin{tabular}{|c|c|c|}
\hline \multicolumn{3}{|c|}{ Exportaciones Mundiales de Servicios Comerciales } \\
\hline 1995 & 2005 & 2015 \\
\hline 1,179 Billones USD & 2,516 Billones USD & 4,872 Billones USD \\
\hline \multicolumn{3}{|c|}{ Exportaciones Mundiales de Mercancias } \\
\hline 1995 & 2005 & 2015 \\
\hline 5,168 Billones USD & 10,509 Billones USD & 19,002 Billones USD \\
\hline
\end{tabular}

Fuente: Elaboración propia con datos de la Organización Mundial del Comercio (OMC, s.f.) 
La tabla 1 muestra la evolución en valores totales de los últimos 20 años, en el caso del comercio de servicios al hacer la comparación de 2005 con respecto a 1995 se observa que este experimentó un crecimiento del 53\%, al compararse el 2015 con relación al 2005 el crecimiento fue menor (48\%) pero siempre con datos de crecimiento favorables.

Las exportaciones mundiales de mercancías en el período 1995 - 2005 crecieron 51\% un valor muy significativo, en cambio de 2005 a 2015 el crecimiento fue de apenas 45\%, lo cual se debe principalmente a factores como la crisis económica de 2008 y, además de ello, el aumento del precio del petróleo en 2010 debido principalmente a la inestabilidad política de los países productores de petróleo (la denominada primavera árabe) obstaculizó la recuperación del comercio mundial de mercancías (Comercio, 2015).

Estos datos evidencian el ímpetu de los países en incrementar más su participación en el comercio internacional, por ello el rol de los tratados de libre comercio desempeñan un papel fundamental para el desarrollo del comercio internacional facilitando así las transacciones entre los países y estableciendo ventajas comparativas y absolutas entre los signatarios.

Los países centroamericanos han buscado desde hace mucho tiempo lograr una unión económica, proceso que se ha acelerado en los últimos meses con la Unión Aduanera entre Guatemala y Honduras, a la cual se unirá próximamente El Salvador. Estos países que además pretenden unificar los tratados de libre comercio que tienen actualmente con la Republica de China (Taiwán) de forma individual. El objetivo de esta investigación es Analizar el impacto económico y social de las relaciones comerciales de Taiwán con el Triángulo Norte de Centroamérica.

\section{MARCO TEORICO}

Las relaciones comerciales entre países han recorrido un largo camino desde el trueque hasta la difícil especialización $y$ diversificación. A continuación, se mencionan algunas de las etapas más importantes del comercio.

\subsection{El mercantilismo}

La primera teoría del comercio internacional surgió en Inglaterra a mediados del siglo XVI. Conocida como mercantilismo, su declaración de principios consistía en que el oro y la plata eran los pilares fundamentales de la riqueza nacional y eran esenciales para un comercio vigoroso. El principio fundamental planteaba que era conveniente para un país mantener un excedente de comercio, a través de un mayor nivel de exportación que de importación. Al hacerlo, un país acumularía oro $y$ plata $e$ incrementaría su riqueza y prestigio nacionales (Hill, 2011). 
2.2 Teoría de la Ventaja Absoluta

Adam Smith en su obra clásica “The Wealth of Nations" de 1776, argumentaba que los países deben especializarse en la producción de mercancías para las que tengan una ventaja absoluta $y$, posteriormente intercambiar estos productos por artículos producidos por otros países, nunca se debe producir en casa lo que se pueda adquirir, a un menor costo, de otros países (Smith, 1776). Esta teoría a pesar de ser la primera en considerar la especialización como un factor estratégico para los países, tomaba ésta sólo a nivel de país entero, no a nivel de regiones.

2.3 Teoría de la Ventaja Comparativa

David Ricardo demostró que un país debe especializarse en aquellos bienes y servicios que pueda producir de manera más eficiente y adquirir, de otros países aquellos que produzca de manera menos eficiente, incluso cuando, en ocasiones, esto represente adquirir bienes extranjeros cuya producción final puede ser más eficiente (Ricado, 1967). De esta manera, la teoría de David Ricardo hace énfasis en la productividad de los países.

\subsection{Teoría de Heckscher-Ohlin}

Los economistas suecos Eli Heckscher, en 1919, y Bertil Ohlin, en 1933, expusieron una explicación distinta de la ventaja comparativa. Ambos aseveraron que la ventaja comparativa es producto de las diferencias en la dotación de factores (tierra, mano de obra y capital) Distintas dotaciones de factores explican las diferencias en los costos relativos a los factores. Entre más abundante es un factor, menor es su costo. Los países exportarán aquellos bienes que hacen uso intensivo de aquellos factores localmente abundantes, e importarán bienes que hacen uso intensivo de aquellos factores localmente escasos. (Jonhes, 1984).

2.5 Teoría del Ciclo de Vida del Producto Raymond Vernon propuso la teoría del ciclo de vida del producto a mediados de los años sesenta. La teoría sugiere que en las fases tempranas del ciclo de vida del producto la producción se lleva a cabo en el mismo lugar donde fue inventado y se exporta a países similares en nivel de desarrollo y preferencias de la demanda. En una segunda etapa aparecen copias del producto que se producen en otros países y se introducen en el país de origen.1 En la tercera etapa, llamada de madurez, el mercado deja de crecer y sólo se mantienen las empresas que logran producir con menores costes. En la cuarta etapa, sólo los países con menor nivel de desarrollo producen y comercializan el producto en su propio territorio (Vernon, 1966).

\subsection{La Nueva Teoría del Comercio}

La nueva teoría del comercio surgió cuando varios economistas en la década de 1970 señalaron "que la capacidad de las empresas 
de alcanzar economías de escala tendría implicaciones importantes para el comercio internacional"

(Elhanan, 1986). Las economías de escala son reducciones de los costos unitarios que se obtienen con grandes volúmenes de producción. Las economías de escala proceden de varios orígenes, como la capacidad de prorratear los costos fijos en un volumen cuantioso, y la de los grandes productores de recurrir a trabajadores y equipos especializados más productivos (Krugman, 1992).

La nueva teoría del comercio internacional presenta dos puntos importantes. En primer lugar, el comercio, el comercio, por su defecto en las economías de escala, aumenta la variedad de productos que se ofrecen a los consumidores y se reduce sus costos. En segundo, en los sectores en que el requisito de la producción alcance economías de escala representa una proporción significativa de la demanda mundial total, el comercio mundial solo soporta pocas empresas. Por ello el comercio mundial de algunos productos es dominado por países que iniciaron su producción.

\section{METODOLOGÍA Y FUENTE DE DATOS}

El presente trabajo es de carácter no experimental, con un alcance descriptivo, de corte transversal. Responde a una caracterización del comportamiento de las relaciones comerciales de Taiwán con Honduras, Guatemala y El Salvador, desde una perspectiva económica.

El universo de datos se obtiene principalmente de fuentes oficiales que tienen la responsabilidad de generar estadísticas de exportación e importación, por ejemplo, el Banco Central de Honduras, el Banco central de Reserva de El Salvador, el Banco de Guatemala y Dirección General de Presupuesto, Contabilidad y Estadística, Yuan Ejecutivo, República de China.

\section{RESULTADOS}

\subsection{Economía Taiwanesa}

En la actualidad Taiwán se ha consolidado como una de las entidades económicas y comerciales más importantes en el mundo, a pesar de las dificultades que Taiwán enfrenta en lo político y diplomático la isla ha diseñado acertadamente una política comercial con la cual ha logrado establecer un posicionamiento internacional privilegiado, debido a que las relaciones comerciales han sido manejadas al margen de las relaciones políticas. Taiwán comercia con productos de alto valor agregado, esto hace posible que los productos lleguen a todo tipo de mercados; es decir, no solo se comercia en países desarrollados, sino también, países en vías de desarrollo, como el caso de Honduras.

La estructura económica taiwanesa se fundamenta en varios pilares, enmarcados en 
los tres sectores de la economía. El sector primario de la economía taiwanesa es limitado, debido al tamaño de la isla, sin embargo, casi la totalidad de la tierra se explota, los productos agroalimentarios que se producen, principalmente en la isla, son el arroz (el cual es autosuficiente) la caña de azúcar, frutas y hortalizas.

El sector secundario está caracterizado principalmente por el impulso de industrias como la electrónica y las tecnologías de información, la optoelectrónica (medios de almacenamiento óptico visualizadores digitales), nanotecnología y biotecnología, y la industria energética.

Finalmente, el sector terciario de la economía con respecto al PIB en 1990 fue de $60.2 \%$ pasando a un $68.6 \%$ en 2014, siendo la hostelería, la banca, los seguros y las telecomunicaciones, los servicios que mayor crecimiento generaron a la economía de Taiwán.

Tras el ingreso de Taiwán a la OMC y la firma del EFCA1 con China se han creado diversas oportunidades en el sector servicios, los subsectores más importantes son los de la banca de seguros y el ocio. El poder adquisitivo de los taiwaneses ha incrementado significativamente en las últimas dos décadas y la influencia de la cultura occidental está transformando los

1 Economic Cooperation Framework Agreement Acuerdo de Comercio Preferencial entra los gustos del consumidor taiwanés, además los hábitos de consumo están cambiando y cada vez se le da más importancia al ocio con más de 4 millones de turistas provenientes solo de China continental en 2015 (Rueda, 2015).

\subsection{La Política Comercial Taiwanesa}

La política comercial se define como el manejo de un conjunto de instrumentos al alcance del Estado para mantener, alterar o modificar sustantivamente las relaciones comerciales de un país con el resto del mundo (Krugman, 1980). Esta herramienta puede ser clave para lograr el desarrollo económico de un país al permitir la diversificación industrial y la creación de un mayor valor agregado.

En la actualidad, las tendencias internacionales hacia la apertura de mercados han hecho que se reduzcan los aranceles en forma significativa, aparentemente en pro de conjugar un mercado internacional (Krugman, 2008).

Los factores que inciden en la competitividad de la política comercial están determinados por la magnitud del comercio internacional, el valor monetario del comercio exterior, la relevancia nacional del comercio exterior, las barreras no arancelarias y las demoras al comercio internacional (Chavez, 2012)

Gobiernos de China Taiwán y la República de China (Continental). 
La estrategia de política comercial de Taiwán debe acomodarse para tomar decisiones $y$ formular estrategias dentro de un limitado rango de acción, esto se debe a las condiciones hostiles en las que se encuentra en materia política y diplomática, de estos factores el que más incidencia tiene en la formulación de la estrategia comercial es el hecho de no tener relaciones diplomáticas con la mayoría de los países del hemisferio, actualmente Taiwán es reconocido como Estado únicamente por 20 naciones, las cuales en su mayoría son pequeños Estados que no tienen peso económico o político en el mundo y que mantienen sus relaciones diplomáticas con Taiwán por los beneficios económicos, (Préstamos blandos, capacitación técnica, además de su programa de ayuda exterior y otros asuntos de cooperación)

Los asuntos diplomáticos tienen un impacto directo en la formulación de la política comercial taiwanesa, que hace que dicha política presente características particulares las cuales la convierten en un caso interesante y dinámico, estas características suponen la elaboración de una política comercial cuyas repercusiones y efectos van más allá de las relaciones económicas internacionales. Taiwán urge de medidas como zonas francas, liberación de regímenes de inversión, reducción de barreras no arancelarias, y de este modo buscar ventajas comparativas con otros países (Rueda, 2015), esto sin duda dinamizaría aún más las relaciones comerciales de Taiwán, reducirían costos y precios y al final tendría un impacto positivo en la balanza comercial y por ende en el PIB.

\subsection{Apertura Comercial}

La globalización se establece atendiendo a la evolución del comercio internacional, tomando como medida de referencia el peso relativo del comercio en la producción, también llamado grado de apertura externa o apertura comercial de las economías (OCDE, 2005). Este indicador se define como el porcentaje que inciden en los flujos de comercio exterior exportaciones (X) e importaciones $(\mathrm{M})$ en el total del PIB; es decir:

$(\mathrm{X}+\mathrm{M}) / \mathrm{PIB}{ }^{*} 100$

Atendiendo a su construcción, una economía estará más presente en los mercados internacionales cuando mayor sea su grado de apertura, es decir, cuando mayor sea la participación de las exportaciones más las importaciones en la producción nacional (Paso, 2014). 
Tabla 2 Taiwán: Apertura Comercial 2011 - 2015

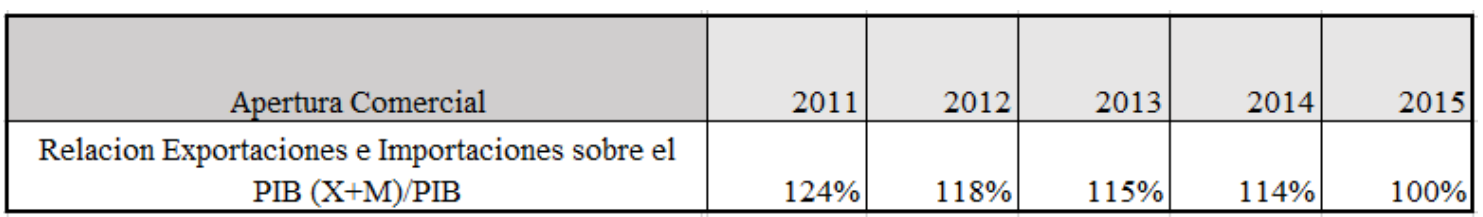

Fuente: Elaboración propia con datos de Directorate - General of Budget, Accounting and Statistics, Executive Yuan, Republic of China (últimas cifras disponibles).

Según los datos de la Dirección General de Presupuesto, Contabilidad y Estadística, Yuan Ejecutivo de la República de China, Taiwán tiene una considerable apertura comercial puesto que el impacto del comercio sobre el PIB fue superior al $100 \%$ en el período 2011 - 2014, sin embargo, se ha observado una disminución sustancial en el porcentaje de apertura comercial para el año 2015 ya que el porcentaje de apertura comercial se redujo de $114 \%$ a $100 \%$, aun experimentado estas disminuciones, la participación en el mercado internacional de Taiwán es sustancial.

La economía taiwanesa se ve impactada principalmente por dos factores, las manufacturas y el comercio, esto se ve reflejado en el detalle de la participación en el PIB por sectores, el cual se detalla a continuación:

Figura 1 Taiwán: Distribución Sectorial del PIB (porcentajes) 2011-2015

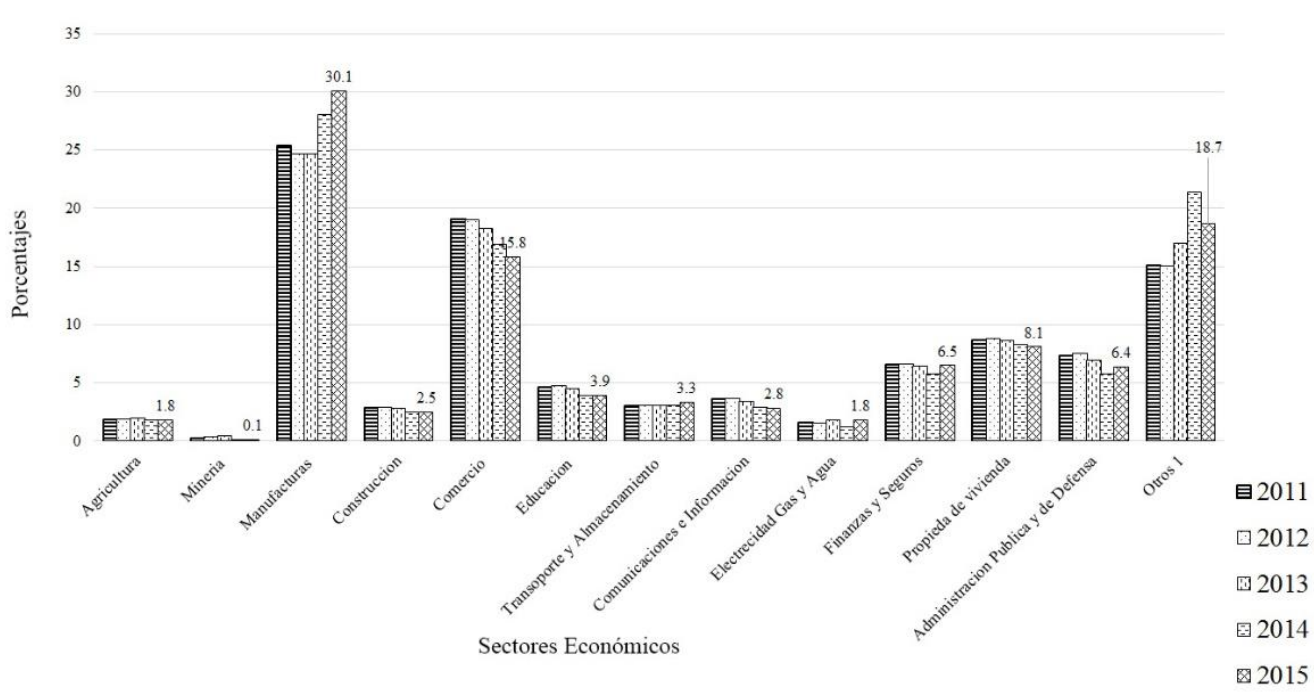

Fuente: Elaboración propia con datos de Directorate - General of Budget, Accounting and Statistics, Executive Yuan, R.O.C. (Taiwán) 
La figura 1 muestra la evolución del PIB por sectores económicos de 2011 - 2015 (últimos datos disponibles), en el cual se ve reflejado el rol determinante que juega el comercio en la economía taiwanesa, siendo únicamente superado por el sector manufacturero; el comercio es un elemento fundamental para la economía en Taiwán, sin embargo, el comercio en los últimos años ha disminuido su impacto en la economía (ver tabla A1 en apéndices).

\subsection{Tratados y Acuerdos}

Acuerdo Marco de Cooperación Económica (Economic Cooperation Framework Agreement EFCA)

En 2010 China y Taiwán suscribieron un acuerdo, lo que se convirtió en un hito en las relaciones de ambas naciones, ya que las relaciones diplomáticas y comerciales entre ambos países eran muy bajas, sin embargo, el grado de intercambio comercial entre Taiwán y China aumentó desde la suscripción del acuerdo, esto se ve reflejado en las exportaciones e importaciones, según Bureau of Foreign Trade ( institución encargada de regular el comercio en Taiwán) en 2016 el $40 \%$ de las exportaciones de Taiwán tuvieron como destino China y el $19 \%$ de sus importaciones proceden de China incluido Hong Kong. Estos datos reflejan la importancia de las relaciones comerciales entre ambas naciones, tanto China representa un importante socio comercial para Taiwán, como Taiwán para China.

\subsection{Acuerdos Comerciales con Centroamérica}

Las relaciones comerciales entre los países de Centroamérica y Taiwán son cada vez más dinámicas, los países de Centroamérica a excepción de Costa Rica y recientemente Panamá, pertenecen a las 20 naciones que aún tienen relaciones diplomáticas con Taiwán, lo que constituye a estos países en aliados y beneficiarios de proyectos de cooperación impulsados por Taiwán. Es la cooperación que reciben los países pequeños (en tamaño y economía) lo que ha permitido que la relación bilateral entre Taiwán y sus aliados aun siga vigente, lo que se ha constituido en una diplomacia de tipo "comercial" o "dolarizada' (Erikson y Chen, 2007) Taiwán ofrece múltiples formas de ayuda, a cambio de mantener su cuota de reconocimiento internacional

Actualmente Honduras, Guatemala, Panamá, Nicaragua y El Salvador cuentan con Tratados de libre Comercio (TLC) con Taiwán, estos tratados tienen un amplio alcance en el espectro comercial y se han suscrito en forma bilateral con cada uno de los países.

El primero en negociar y suscribir un TLC fue Panamá, el cual entró en vigencia en agosto de 2003 (SIECA, 2003), además de esto, fue el 
primer tratado que Taiwán suscribió con otro país dándole una gran cobertura $\mathrm{e}$ importancia al mismo, puesto que representaba el rompimiento en el aislamiento comercial (Tratados Comerciales) y además representaba el inicio de la inserción en la suscripción de tratados de libre comercio, por lo tanto, marcó una nueva etapa en la política comercial taiwanesa (el tratado se derogó automáticamente con el rompimiento de las relaciones diplomáticas entre estos países).

Después de la suscripción del TLC con Panamá, otros países centroamericanos suscribieron tratados comerciales, quedando como modelo para las siguientes negociaciones con otros países. El siguiente país centroamericano fue Guatemala, este tratado bilateral entró en vigencia a partir del 1 de enero de 2006. Este acuerdo fue estratégico, Taiwán buscaba un socio comercial que permitiera un acceso más sencillo a los mercados internacionales como Estados Unidos. Guatemala por su parte, buscó una oportunidad para ampliar su mercado exportable y así penetrar en el mercado asiático (Rueda, 2015).

Siguiendo el mismo modelo y ejemplo guatemalteco, El Salvador y Honduras comenzaron a negociar un TLC con la República de Taiwán. En los años 2006-2007, se negoció el tratado y entró en vigencia a partir del 1 de enero de 2008 en el caso de El Salvador - Taiwán y el 15 de julio de 2008 en el caso de Honduras - Taiwán. Fruto de estos tratados los países de Guatemala, El Salvador y Honduras (Triángulo Norte de Centroamérica) agilizaron su comercio (exportaciones e importaciones) hacia el país asiático.

4.6 Estadísticas de Intercambio Comercial Honduras, El Salvador y Guatemala - Taiwán

La Figura 2 muestra el intercambio comercial histórico entre la República de Honduras y Taiwán, en la cual se puede observar la evolución significativa del comercio bilateral, en el período 2008 - 2009, a pesar de que fue el año en el cual entró en vigencia el TLC tanto las exportaciones como las importaciones disminuyeron, esto se atribuye esto a la crisis política de Honduras por el golpe de Estado. En 2015 las importaciones alcanzaron su nivel máximo (\$115.40) millones, en cuanto a las exportaciones el volumen más alto fue en 2014 (\$35.60 millones). 
Figura 2. Honduras - Taiwán: Intercambio Comercial 2005 - 2016

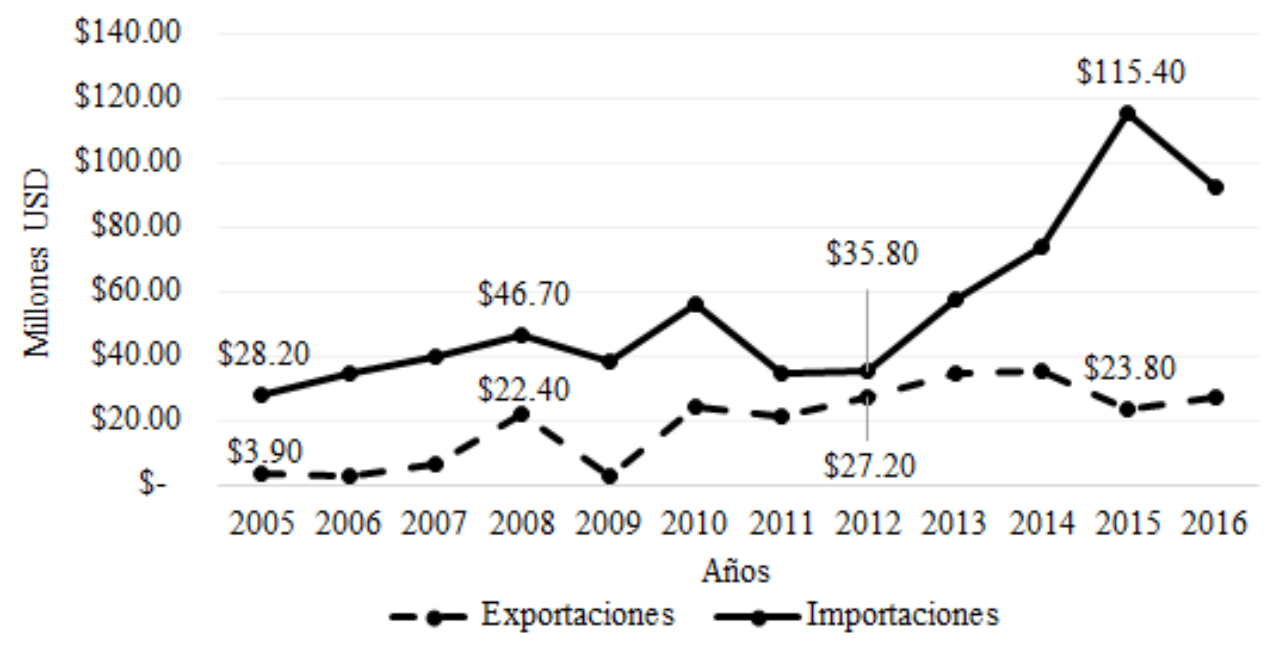

Fuente: Elaboración propia con datos de Banco Central de Honduras 2005-2016

Figura 3 Guatemala - Taiwan: Intercambio Comercial 2005 - 2016

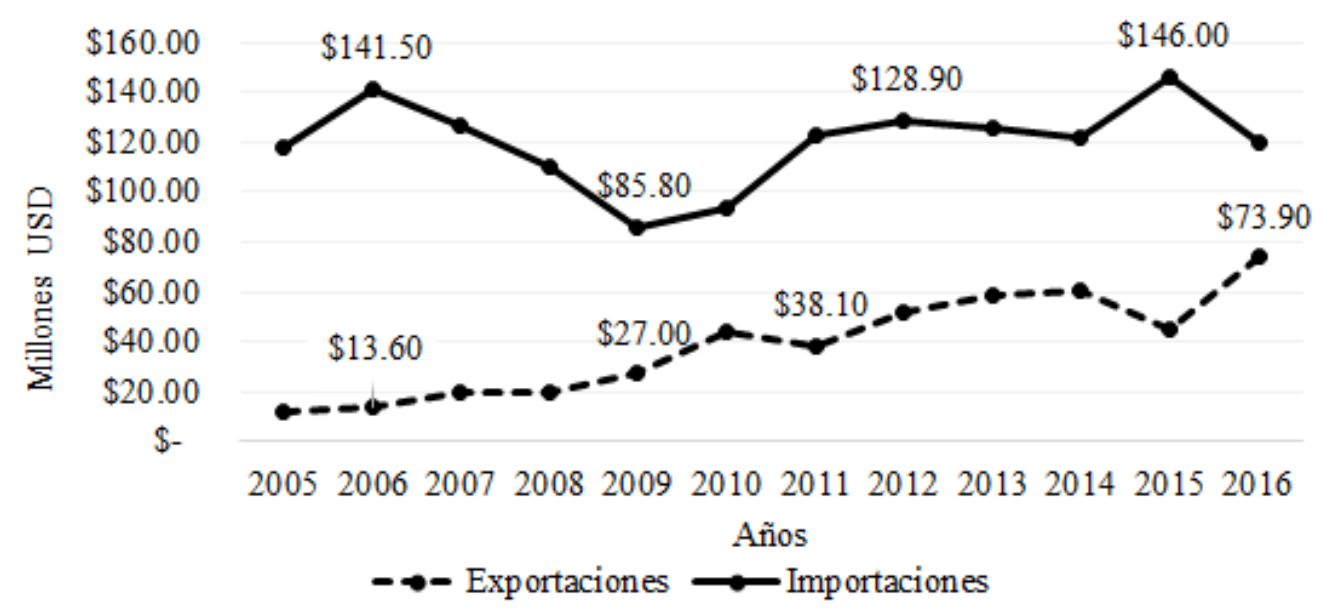

Fuente: Elaboración propia con datos de Banco de Guatemala 2005-2016

La figura 3 muestra las exportaciones e importaciones entre Guatemala y Taiwán; según el Banco de Guatemala, al igual que Honduras la Balanza Comercial de Guatemala con Taiwán es deficitaria, sin embargo, en comparación con Honduras históricamente Guatemala exporta mayor volumen y valor mercancías a Taiwán. Para hacer una comparación, en el año 2010 las exportaciones hondureñas a Taiwán fueron de \$24.50 millones de dólares, mientras que las de Guatemala fueron de $\$ 43.70$ millones, superando a las exportaciones hondureñas en $\$ 19.2$ millones. Con respecto a 2016 las 
exportaciones hondureñas sumaron $\$ 27.40$ millones, por su parte Guatemala exportó $\$ 73.40$ millones, superando a Honduras por $\$ 50$ millones, lo que demuestra un amplio margen las exportaciones entre un país y otro. Las importaciones guatemaltecas al igual que las exportaciones son superiores a las de Honduras, en el año 2016 Guatemala importó de Taiwán productos con un valor total de $\$ 119.70$ millones, mientras que Honduras importó \$92.70 una diferencia estimada de \$27 millones.

Luego de haber suscrito el tratado las exportaciones guatemaltecas hasta 2016 habían crecido $82 \%$, un crecimiento superior al experimentado por Honduras (77\%), las importaciones de Guatemala tuvieron variaciones positivas y negativas, si se compara 2016 con 2006 se observa un descenso en las importaciones de aproximadamente $18 \%$ comparando los $\$ 119.70$ millones de 2016, con los \$141 millones importados en 2006. Es importante destacar que en 2016 las exportaciones guatemaltecas crecieron y las importaciones disminuyeron, esto es un avance positivo para la balanza comercial del país centroamericano (ver tabla A3 en apéndice A).

Figura 4 El Salvador Taiwán: Intercambio Comercial 2005 - 2016

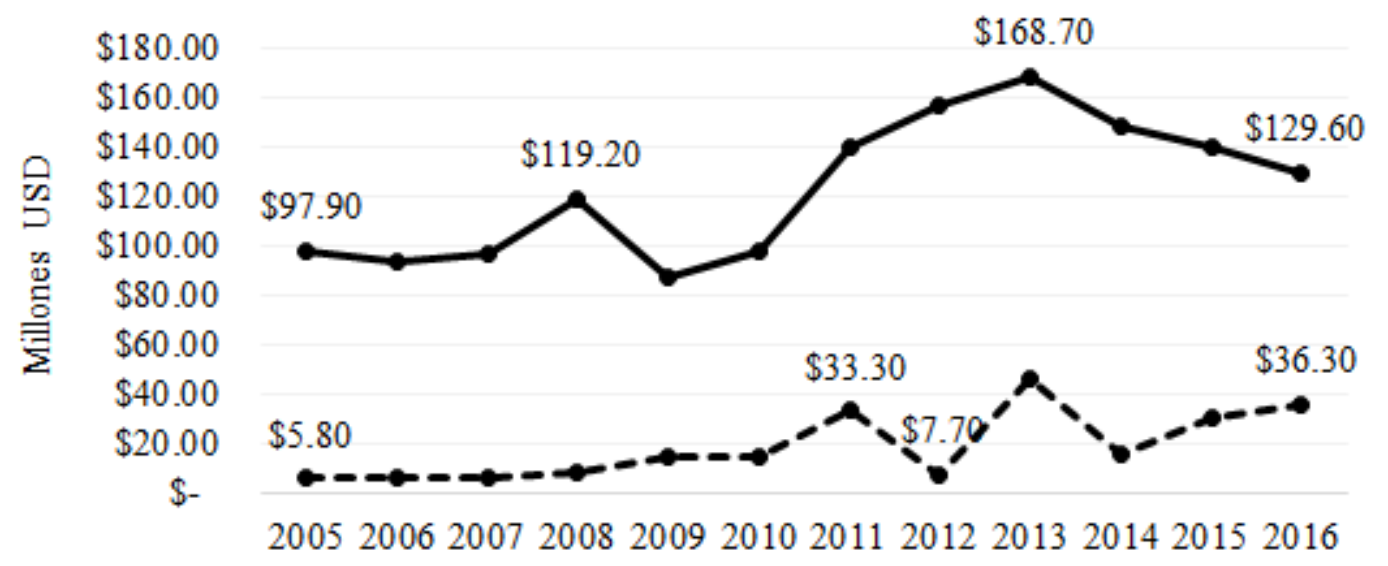

$\leadsto-$ Exportaciones $\longrightarrow$ Importaciones

Fuente: Elaboración propia con datos del Banco Central de Reserva de El Salvador 2005-2016

En la figura 4 muestra las exportaciones e importaciones entre El Salvador - Taiwán en las cuales se aprecia que El Salvador es actualmente el mayor importador de mercancías de Taiwán, comparándolo con sus vecinos de Guatemala y Honduras, sin 
embargo, la balanza comercial es deficitaria por más de 93 millones de dólares, lo que denota la desigualdad entre exportaciones e importaciones y la excesiva varianza entre un indicador y otro, sin embargo, su volumen y valor de exportaciones superan al de Honduras, el cual históricamente a partir de la suscripción del tratado (2008) en términos porcentuales las exportaciones han tenido una varianza positiva de $78 \%$ mientras que las importaciones tuvieron un crecimiento de un 8\% (ver tabla $\mathrm{A} 4$ en apéndice $\mathrm{A}$ )

Luego de analizar el intercambio comercial entre los países del triángulo norte de Centroamérica y Taiwán se puede concluir que el país que mayor participación tiene en cuanto a relaciones comerciales es Guatemala, el cual presenta los índices más altos de exportación en la región (comparar tablas A2, A3 y A4 en apéndice A).

Los tres países del Triángulo Norte (Honduras, Guatemala y El Salvador) presentan condiciones similares en cuanto a su intercambio comercial con el país asiático, todos tienen déficits comerciales y las importaciones tienen una gran brecha de diferencia con respecto a las exportaciones, uno de los factores que influye en este fenómeno es el hecho de que los productos importados de Taiwán cuentan con un alto valor agregado, situación que puede lograr incrementar su valor en los mercados centroamericanos, según datos del Sistema de
Integración Económica Centroamericano (SIECA, s.f.).

\subsection{Productos de intercambio comercial Triángulo Norte-Taiwán}

En la figura 5 se observa la evolución de las importaciones de los principales productos originarios de Taiwán; hasta 2012 los automóviles, tractores y otros vehículos terrestres eran los productos que más se compraban a Taiwán, tendencia que fue cambiando a partir de 2013, en donde la tendencia que cambió por plásticos y sus manufacturas. Otro sector que fue aumentando su participación en el mercado hondureño y que en los últimos tres años fue ganando importancia son los reactores nucleares, calderas, aparatos y artefactos mecánicos, las máquinas, aparatos y material eléctricos (ver tabla A6 en apéndice A).

Estos productos se evidencian en el sector manufacturas de la República de Taiwán (sector que tiene mayor participación en el PIB),

Por su parte Honduras exporta a Taiwán en grandes cantidades pescados crustáceos y moluscos, desde 2012 este tipo de productos se han constituido como los más exportados a Taiwán, debido al alto consumo de animales marinos en el continente asiático, la pasta de madera, papel o cartón, el café, té y especias y la fundición de hierro y acero, son los productos hondureños que según SIECA tiene una participación más importante en el 
mercado asiático específicamente en Taiwán. (Ver tabla A5 en apéndice A).

La diferencia entre los productos exportados por Honduras a Taiwán en comparación con los importados es el alto valor agregado $y$ nivel de industrialización de los productos que Taiwán vende, no solo a los países centroamericanos, sino al resto del mundo, en cambio los productos que Honduras vende a Taiwán son productos o bienes commodities, los cuales son bienes de bajo costo de producción y, por lo tanto, su precio de mercado también es bajo.

Figura 5 Honduras - Taiwán: Distribución porcentual de los principales productos importados y exportados 2010 - 2016 (septiembre)

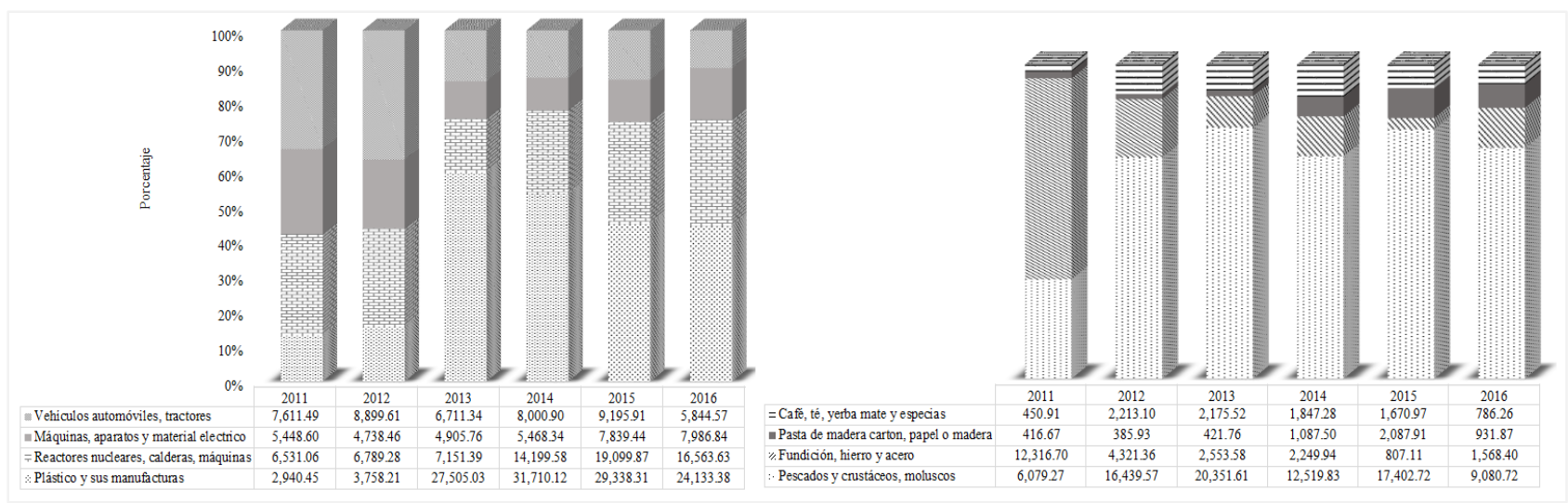

Fuente: Elaboración propia con datos de SIECA

Figura 6 Guatemala - Taiwán: Distribución porcentual de los principales productos importados y exportados 2011- 2016 (septiembre)

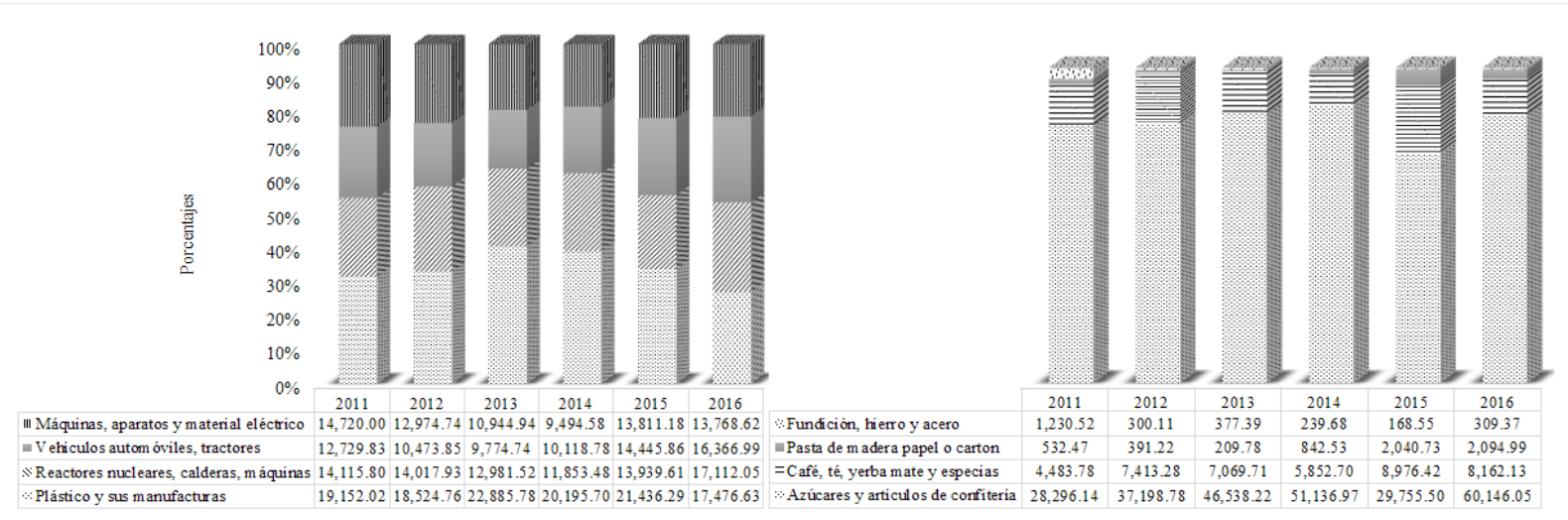

Fuente: Elaboración propia con datos de SIECA 
Al igual que Honduras, Guatemala envía a Taiwán productos de bajo costo y obtenidos de recursos naturales (ver figura 6) como el café, té, azucares, artículos de confitería, pasta de madera, hierro y acero, siendo los azucares y artículos de confitería los productos que mayor demanda el mercado taiwanés de Guatemala. Las importaciones guatemaltecas desde Taiwán se constituyen principalmente por plástico y sus manufacturas, máquinas y aparatos eléctricos, vehículos, automóviles tractores, reactores nucleares calderas y máquinas, todos estos productos tienen un alto valor agregado lo que los convierte en bienes de alto costo, al comercializarse en otros países, sin embargo, al existir un TLC, estos precios disminuyen sustancialmente. (Ver tablas A9 y A10 en apéndice A).

Figura 7 El Salvador - Taiwan: Distribucion porcental de los principales productos importados y exportados 2011 - 2016 (septiembre)

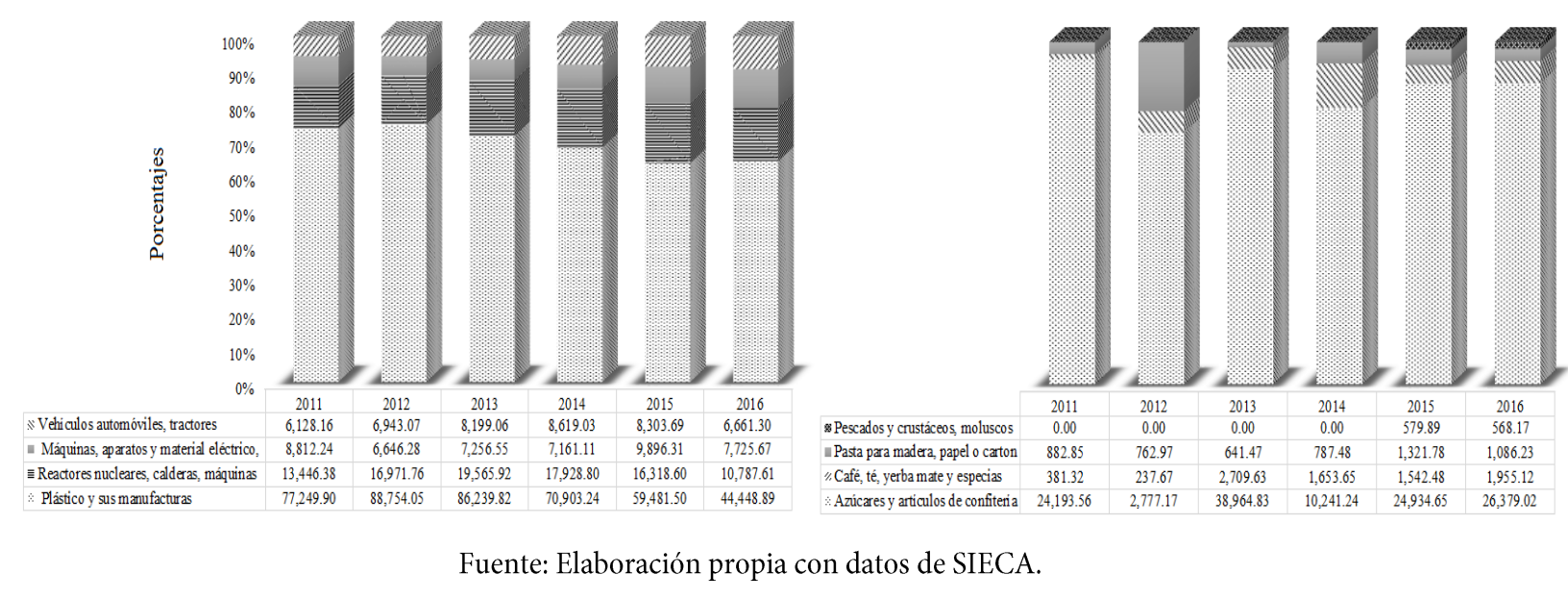

En la figura 7 se observan los principales productos importados por El Salvador desde Taiwán, los cuales incluyen vehículos, automóviles, tractores, maquinas aparatos y material eléctrico, reactores nucleares calderas y plásticos y sus manufacturas. Estos productos son propios de la industria de Taiwán, demuestran su nivel de avance tecnológico, reflejado en los productos exportados al extranjero.

El Salvador vende a Taiwán pescados, crustáceos, moluscos, pasta para madera papel cartón, café, té, yerba mate, especias, azucares y artículos de confitería (ver tablas A7 y A8 apéndice A). Se puede decir que en esta tendencia de exportaciones e importaciones evidencia la ventaja comparativa, la cual indica que un país debe especializarse en los bienes que produce con 
mayor eficiencia y compre a otros países lo que produce menos eficientemente (Ricardo, 1817), los países centroamericanos cuentan con una gran riqueza natural, y venden productos del sector primario de la economía con un nivel bajo o nulo de industrialización, mientras que Taiwán se especializa en vender productos tecnológicos, con alto valor monetario y alto valor agregado.

\subsection{Importancia Comercial de Taiwán} para el Triángulo Norte de Centroamérica

El Triángulo Norte de Centroamérica tiene características muy similares en términos comerciales, uno de los elementos en los cuales tienen similitudes es en los principales socios comerciales, dentro de los cuales se identifica a Estados Unidos como el principal socio comercial de los tres países, el resto de los países centroamericanos son también principales socios comerciales entre sí. Para el caso de Honduras Alemania es su tercer socio comercial (ver tablas A11, A12 y A13 en apéndice $\mathrm{A}$ )

Taiwán no tiene un alcance comercial tan alto en los países centroamericanos en el caso de Guatemala, Honduras y El Salvador, representa únicamente el $1 \%$ de las transacciones comerciales de exportación (ver figura 8).

Taiwán no está dentro de los 10 principales socios comerciales de El Salvador Guatemala o Honduras, pero estos países son aliados políticos y diplomáticos de Taiwán lo que puede hacer que las relaciones comerciales se manejen con mayor eficacia. Las relaciones de los países del triángulo norte de Centroamérica van más allá de lo comercial y se concentran en la cooperación. Los campos sociales, culturales y políticos son puntos de convergencia entre los Estados del Triángulo Norte y Taiwán.

Figura 8 porcentaje representativo de Taiwán en Honduras, El Salvador y Guatemala por volumen de exportaciones

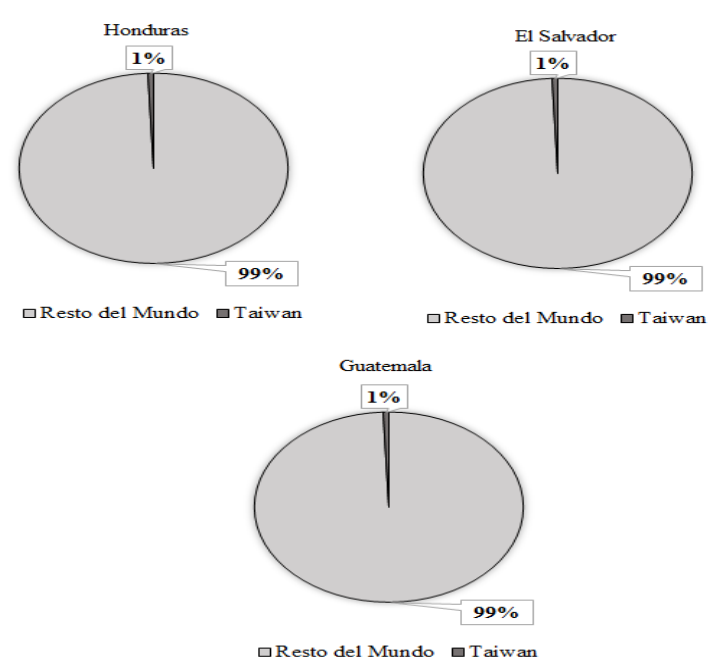


4.9 Rumbos de las Relaciones comerciales de Taiwán con Honduras

En el marco de la visita de la presidenta taiwanesa Tsai Ing-wen (Enero 2017) la Secretaria de Desarrollo Económico e Inclusión Social dio a conocer el interés en suscribir un nuevo TLC con la República de Taiwán, en la cual formarían parte los países de Guatemala, El Salvador y Honduras; de esta manera, habría una unificación entre los tratados ya existentes, lo que agilizaría las relaciones comerciales entre los países miembros, además, las "reglas del juego" cambiarían significativamente con la suscripción de un nuevo TLC.

Para profundizar y tener un panorama claro sobre lo que se espera al suscribir un nuevo TLC se realizaron entrevistas a la unidad de Negociaciones de Tratados de la Secretaria de Desarrollo Económico de Honduras y en la cual los expertos respondieron lo siguiente:

Jorge Pinel asesor de Dirección de Tratados manifestó que al suscribir un nuevo acuerdo multilateral "En general se busca ampliar el alcance del tratado de libre comercio, en ese sentido se espera una mayor desgravación arancelaria, en menor tiempo posible y con alcance para el mayor número de productos posible"

Como partes de los beneficios del nuevo TLC se pretende "aumentar las cuotas exportables de algunos productos, lo que beneficiaria económicamente a algunos sectores como el azucarero, camaronero, textil, agroindustrial, entre otros, esto lógicamente impactaría positivamente a las regiones en las cuales se produzcan estos bienes, y se vería reflejado en el incremento de los empleos, economías más dinámicas y una mayor producción local, para crear una mayor oferta exportable" también es de suma importancia mencionar que "La cooperación taiwanesa ha jugado un papel importante en el país en los últimos años, principalmente en materias de apoyo técnico y monetario orientado con prioridad hacia las MYPIMES del país estos fondos generan beneficio social con el surgimiento de nuevas empresas las cuales a la postre generaran empleos".

Uno de los mayores beneficios de la suscripción de tratados es el percibido por los exportadores por lo cual "De suscribirse un nuevo TLC se buscarían las estrategias oportunas para promover más las exportaciones a un mercado prometedor como lo es el mercado taiwanés y para que los empresarios hondureños aprovechen los beneficios derivados del mismo".

"En cuanto a los tributos se produciría lo que se denomina un "sacrificio fiscal" porque se dejan de percibir tributos por las exportaciones e importaciones, mismas que se recuperan en parte a través del impuesto sobre ventas" (Pinel, 2017). 
Por su parte el licenciado Cesar Díaz quien funge como director de Negociaciones de la Secretaria de Desarrollo Económico declaró que "lo que se pretende es realizar un estudio en el cual se buscaría la convergencia que existe en los tres tratados ya suscritos y de esta manera unificar los reglamentos" (Diaz, 2017).

\section{CONCUSIONES}

Las relaciones comerciales internacionales son una herramienta de desarrollo que los países implementan con el objetivo principal de generar crecimiento económico. Los índices económicos alcanzados por los países asiáticos los convierten en una región atractiva para establecer relaciones comerciales. Existe un grupo de países que se destacan sobre los demás, es el caso de Hong Kong, Singapur Corea del Sur y Taiwán, conocidos como los cuatro tigres asiáticos. Sus estrategias esta orientadas hacia los avances tecnológicos, políticas sustitutivas de importación orientándose luego a las exportaciones, demostrando crecimiento en calidad, cantidad y bajos precios de sus productos, alcanzando mercados internacionales y cambiando paradigmas mundiales

Taiwán actualmente tiene una leve participación en los intercambios comerciales de los países del triángulo norte de Centroamérica, sin embargo, las relaciones de los países (Honduras,
Guatemala y El Salvador) con Taiwán van en ascenso, impulsadas principalmente por las políticas de cooperación implementadas por el gobierno de Taiwán, los cuales, benefician a muchos ciudadanos y empresarios de la región, esto convierte a Taiwán más que en un aliado comercial, en un aliado estratégico para Guatemala Honduras y El Salvador y a estos países en aliados diplomáticos para Taiwán.

Las implicaciones de cualquier país al reconocer como Estado a Taiwán se derivan básicamente en no reconocer a China (continental) como tal, las cuales de una $\mathrm{u}$ otra manera terminan afectado las relaciones comerciales con dicho país, China es quizá un mejor prospecto como socio comercial, sin embargo, Taiwán es definitivamente un mejor socio diplomático y un mejor apoyo en materia de cooperación, en esto se fundamenta la solidez de las relaciones triangulo norte de Centroamérica - Taiwán.

Los rumbos que tomarán las relaciones comerciales de Taiwán con Honduras, El Salvador y Guatemala se fundamentan en el interés de analizar la convergencia en los tratados existentes de forma unilateral de Guatemala, Honduras y El Salvador; interés que radica en el objetivo de lograr suscribir un nuevo TLC de carácter multilateral, pretendiendo así lograr un incremento de los flujos comerciales entre los países y de esta manera beneficiar a diferentes sectores 
económicos y por ende contribuir al desarrollo humano de la región.

El principal objetivo de suscribir un nuevo TLC es buscar la aceleración de la desgravación arancelaria, se establecerían mejores medidas de salvaguardia, normas de origen entre otros, esto agilizaría las relaciones comerciales entre los países, pero además de estos factores las "reglas del juego" cambiarían con la suscripción de un nuevo TLC.

\section{REFERENCIAS \\ BIBLIOGRÁFICAS}

Affairs, M. o. E., 2017. Bureau of Foreign Trade.

[En

línea]

Available

at:

http://www.trade.gov.tw/English/

[Último acceso: 19 Abril 2017].

Anon., 2017. Directorate - General of Budget, Accounting and Statistics, Executive Yuan, Republic of China. [En línea] Available at:

https://eng.dgbas.gov.tw/mp.asp?mp=2

[Último acceso: 17 Mayo 2017].

Anon., 2017. Ministry of Fiance Republic of China (Taiwan). [En línea] Available at: https://www.mof.gov.tw/Eng/Pages/List.asp $\underline{x}$ ?nodeid $=318$

[Último acceso: 12 Mayo 2017].

Chavez, J. C. L. N., 2012. La competitividad de la política comercial en la economía internacional a traves del analisis de los componentes principales. Investigacion $y$ Ciencia, Issue 54, pp. 40-48.

Comercio, O. M. d., 2015. Estadísticas de Comercio Internacional 2015: Enfoque Especial el Comercio Mundial y la OMC 19952014, Suiza: s.n.

Daniel P. Erikson, J. C., 2007. China, Taiwan, and the Battle for Latin America. The fletcher forum of world affairs, Volumen 31:2.

Diaz, C., 2017. Relaciones comerciales de Honduras con Taiwan: Un nuevo TLC [Entrevista] (3 Julio 2017).

Economicos, S. d. E., 2007. Banco Central de Honduas. [En línea] Available at:

http://www.bch.hn/download/honduras_en

cifras/hencifras2003 2007.pdf

[Último acceso: 29 Marzo 2017].

Economicos, S. d. E., 2008. Banco Central de Honduras. [En línea] Available at:

http://www.bch.hn/download/honduras en cifras/hencifras2006 2008.pdf

[Último acceso: 29 Marzo 2017].

Economicos, S. d. E., 2009. Banco Central de Honduas. [En línea] Available at:

http://www.bch.hn/download/honduras_en

cifras/hencifras2007 2009.pdf

[Último acceso: 29 Marzo 2017]. 
Economicos, S. d. E., 2010. Bnaco Central de Honduras.

[En línea]

Available at:

http://www.bch.hn/download/honduras_en

_cifras/hencifras2008_2010.pdf

[Último acceso: 29 Marzo 2017].

Economicos, S. d. E., 2011. Banco Central de

Honduras.

[En línea]

Available

at:

http://www.bch.hn/download/honduras en

cifras/hencifras2008_2010.pdf

[Último acceso: 29 Marzo 2017].

Economicos, S. d. E., 2013. Banco Central de Honduras. [En línea]

Available at:

http://www.bch.hn/download/honduras_en

cifras/hencifras2011 2013.pdf

[Último acceso: 29 Marzo 2017].

Economicos, S. d. E., 2014. Banco Central de Honduras. [En línea] Available at:

http://www.bch.hn/download/honduras_en

cifras/hencifras2012 2014.pdf

[Último acceso: 29 Marzo 2017].

Economicos, S. d. E., 2015. Banco Central de Honduras. [En línea] Available at: http://www.bch.hn/download/honduras_en cifras/hencifras2013 2015.pdf

[Último acceso: 29 Marzo 2017].

Elhanan, H. P. K., 1986. Market Structure and Foreign Trade: Increasing Returns, Imperfect
Competition and the International Economy. Boston: s.n.

Guatemala, B. d., 2017. Banco de Guatemala. [En línea] Available at: http://www.banguat.gob.gt/inc/ver.asp?id=/e staeco/comercio/sercom/1_POR_PAIS/X_P AIS 1994 2016.htm

[Último acceso: 29 Marzo 2017].

Hill, C. W. L., 2011. Teoria del Comercio Internacional. En: Negocios Internacionales. Competencia en el mercado Global. México: Mc Graw Hill, pp. 156-171.

Honduras, B. C. d., 2017. Sistema de Informacion de Comercio Exterior. [En línea] Available at: https://see.bch.hn/SICE/ConsultaSACAjusta do.aspx

[Último acceso: 4 Abril 2017].

Honduras, B. C. d., 2017. Sistema Integrado de Comercio Exterior. [En línea] Available at: https://see.bch.hn/SICE/ConsultaSACAjusta do.aspx

[Último acceso: 15 Junio 20017].

Jonhes, R. J. P. N., 1984. The positive Theory of International Trade. Amsterdam: s.n.

Krugman, P., 1980. Scale of Economies, Product Differentiation, and the Pattern of Trade.. The American Economic Review, 70(5), pp. 950-959. 
Krugman, P., 1992. Does the New Trade

Economy Require a New Trade Policy?. En:

World Economy. s.l.:s.n., pp. 423-441.

Krugman, P., 2008. Economia Internacional

Teoria y Politica. En: España: Pearson, pp. 165-167.

OCDE, 2005. Handbook on Economics Globalization Indicator, Paris: OCDE.

OMC, s.f. Organizacion Mundial del Comercio. [En línea]

Available at:

https://www.wto.org/indexsp.htm

[Último acceso: 20 Julio 2017].

Paso, R. L. d., 2014. Medicion del Grado de Apertura de una Econoía. eXtoikos, Issue 14, pp. 87-88.

Pinel, J., 2017. Relaciones Comerciales de

Honduras con Taiwan: Un nuevo TLC [Entrevista] (3 Julio 2017).

Reserva, B. C. d., 2017. Banco Central de Reserva. [En línea] Available at:

http://www.bcr.gob.sv/bcrsite/result.php

[Último acceso: 29 Marzo 2017].

Ricado, D., 1967. The Principles of Political Economy and Taxation. Homewood: Illinois.

Ricardo, D., 1817. Principios de Economía Política y de Tributación. Londres: Barsa Planeta.
Rueda, S. M., 2015. Universidad de Chile: Instituto de Estudios Internacionales. [En línea]

Available at: http://www.iei.uchile.cl/noticias/110885/laestrategia-de-politica-comercial-de-taiwan [Último acceso: 28 Abril 2017].

SIECA, 2003. Secretaria de Integracion Economica. [En línea] Available at: http://www.sieca.int/General/Default.aspx [Último acceso: 19 Abril 2017].

SIECA, s.f. Sistema de Estadísticas y Análisis de Mercado de Comercio de Centro América SEC-SIECA. [En línea] Available at: http://estadisticas.sieca.int/ [Último acceso: 20 Abril 2017].

Smith, A., 1776. La Riqueza de las Naciones. Madrid: Alianza Editorial.

Vernon, R., 1966. International Investment and International Trade in the Product Life Cycle. En: The Economic Environment of international Business. Englewood: Prentice Hall, pp. 190-207. 


\section{APENDICE A}

Tabla A1 Estructura del PIB según sectores de la Economía 2011 - 2015

\begin{tabular}{|c|c|c|c|c|c|}
\hline ESTRUCTURA DEL PIB & 2011 & 2012 & 2013 & 2014 & 2015 \\
\hline POR SECTORES & $\begin{array}{c}\% \text { Sobre el } \\
\text { PIB }\end{array}$ & $\begin{array}{c}\% \text { Sobre el } \\
\text { PIB }\end{array}$ & $\begin{array}{c}\% \text { Sobre el } \\
\text { PIB }\end{array}$ & $\begin{array}{c}\% \text { Sobre el } \\
\text { PIB }\end{array}$ & $\begin{array}{c}\% \text { Sobre el } \\
\text { PIB }\end{array}$ \\
\hline Agricultura & 1.83 & 1.9 & 2 & 1.8 & 1.8 \\
\hline Mineria & 0.23 & 0.33 & 0.42 & 0.1 & 0.1 \\
\hline Manufacturas & 25.41 & 24.67 & 24.65 & 28.1 & 30.1 \\
\hline Construccion & 2.89 & 2.9 & 2.85 & 2.5 & 2.5 \\
\hline Comercio & 19.09 & 19.06 & 18.3 & 16.9 & 15.8 \\
\hline Educacion & 4.67 & 4.79 & 4.5 & 3.9 & 3.9 \\
\hline Transoporte y Almacenamiento & 3.03 & 3.09 & 3.09 & 3.1 & 3.3 \\
\hline Comunicaciones e Informacion & 3.58 & 3.65 & 3.4 & 2.9 & 2.8 \\
\hline Electrecidad Gas y Agua & 1.59 & 1.56 & 1.82 & 1.2 & 1.8 \\
\hline Finanzas y Seguros & 6.59 & 6.63 & 6.46 & 5.8 & 6.5 \\
\hline Propieda de vivienda & 8.68 & 8.82 & 8.67 & 8.3 & 8.1 \\
\hline Administracion Publica y de Defensa & 7.35 & 7.58 & 6.98 & 5.8 & 6.4 \\
\hline Otros ${ }^{1}$ & 15.06 & 15.03 & 17.01 & 21.4 & 18.7 \\
\hline Totales & 100 & 100.01 & 100.15 & 101.8 & 101.8 \\
\hline \multicolumn{6}{|c|}{$\begin{array}{l}\text { Fuente: Elaboracion propia con datos de Directorate-General of Buget, Accounting and Statistics R.O.C. (ultimas } \\
\text { cifras disponibles 2015). } \\
1 \text { Otros incluye hoteles y restaurantes, servicios profesionales y tecnicos, sanidad y servicios sociales, arte y ocio y } \\
\text { otras partidas sin clasificar }\end{array}$} \\
\hline
\end{tabular}


Tabla A2 Honduras - Taiwán: Exportaciones e Importaciones 2005 - 2016 millones de USD y porcentaje de crecimiento (US\$ Millones)

\begin{tabular}{|c|c|c|c|c|c|}
\hline \multicolumn{6}{|c|}{ Honduras-Taiwan Millones de USD } \\
\hline \multirow[b]{2}{*}{ Año } & \multicolumn{2}{|c|}{ EXPORTACIONES } & \multicolumn{3}{|c|}{ IMPORTACIONES } \\
\hline & Valor Total FOB & $\%$ Crecimiento & Valor & & $\%$ Crecimiento \\
\hline 2005 & 3.90 & & s & 28.20 & \\
\hline 2006 & 2.60 & $-50 \%$ & s & 34.70 & $19 \%$ \\
\hline 2007 & 6.40 & $59 \%$ & s & 39.80 & $13 \%$ \\
\hline 2008 & 22.40 & $71 \%$ & s & 46.70 & $15 \%$ \\
\hline 2009 & 2.90 & $-672 \%$ & $\$$ & 38.60 & $-21 \%$ \\
\hline 2010 & 24.50 & $88 \%$ & s & 56.30 & $31 \%$ \\
\hline 2011 & 21.70 & $-13 \%$ & s & 34.50 & $-63 \%$ \\
\hline 2012 & 27.20 & $20 \%$ & $\$$ & 35.80 & $4 \%$ \\
\hline 2013 & 34.50 & $21 \%$ & s & 57.60 & $38 \%$ \\
\hline 2014 & 35.60 & $3 \%$ & s & 74.20 & $22 \%$ \\
\hline 2015 & 23.80 & $-50 \%$ & $\$$ & 115.40 & $36 \%$ \\
\hline 2016 & 27.40 & $13 \%$ & $\$$ & 92.70 & $-24 \%$ \\
\hline
\end{tabular}

Tabla A3 Guatemala - Taiwán: Exportaciones e Importaciones 2005 - 2016 millones de USD y porcentaje de crecimiento (US\$ Millones)

\begin{tabular}{|c|c|c|c|c|c|c|}
\hline \multicolumn{7}{|c|}{ Guatemala - Taiwán } \\
\hline \multirow[b]{2}{*}{ Año } & \multicolumn{3}{|c|}{ EXPORTACIONES } & \multicolumn{3}{|c|}{ IMPORTACIONES } \\
\hline & & $1 \mathrm{FOB}$ & \% Crecimiento & & & $\%$ Crecimiento \\
\hline 2005 & $\$$ & 12.30 & & $\$$ & 117.60 & \\
\hline 2006 & $\$$ & 13.60 & $10 \%$ & $\$$ & 141.50 & $17 \%$ \\
\hline 2007 & $\$$ & 19.60 & $31 \%$ & s & 126.70 & $-12 \%$ \\
\hline 2008 & s & 19.90 & $2 \%$ & $\$$ & 110.20 & $-15 \%$ \\
\hline 2009 & s & 27.00 & $26 \%$ & s & 85.80 & $-28 \%$ \\
\hline 2010 & $\$$ & 43.70 & $38 \%$ & $\$$ & 93.30 & $8 \%$ \\
\hline 2011 & $\$$ & 38.10 & $-15 \%$ & $\$$ & 122.70 & $24 \%$ \\
\hline 2012 & $\$$ & 52.10 & $27 \%$ & s & 128.90 & $5 \%$ \\
\hline 2013 & $\$$ & 58.80 & $11 \%$ & s & 125.60 & $-3 \%$ \\
\hline 2014 & s & 60.90 & $3 \%$ & s & 121.40 & $-3 \%$ \\
\hline 2015 & s & 44.80 & $-36 \%$ & s & 146.00 & $17 \%$ \\
\hline 2016 & $\$$ & 73.90 & $39 \%$ & s & 119.70 & $-22 \%$ \\
\hline
\end{tabular}


Tabla A4 El Salvador - Taiwán: Exportaciones e Importaciones 2011 -2016 millones USD porcentaje de crecimiento (US\$ Millones)

\begin{tabular}{|c|c|c|c|c|c|}
\hline \multicolumn{6}{|c|}{ E1 Salvador-Taiwan } \\
\hline \multirow[b]{2}{*}{ Año } & \multicolumn{2}{|c|}{ EXPORTACIONES } & \multicolumn{3}{|c|}{ IMPORTACIONES } \\
\hline & Valor Total FOB & $\%$ Crecimiento & & & $\%$ Crecimiento \\
\hline 2005 & 5.80 & & $\$$ & 97.90 & \\
\hline 2006 & 6.00 & $3 \%$ & $\$$ & 93.40 & $-5 \%$ \\
\hline 2007 & 6.10 & $2 \%$ & $\$$ & 97.40 & $4 \%$ \\
\hline 2008 & 8.00 & $24 \%$ & $\$$ & 119.20 & $18 \%$ \\
\hline 2009 & 14.70 & $46 \%$ & $\$$ & 87.40 & $-36 \%$ \\
\hline 2010 & 14.60 & $-1 \%$ & $\$$ & 97.70 & $11 \%$ \\
\hline 2011 & 33.30 & $56 \%$ & $\$$ & 139.70 & $30 \%$ \\
\hline 2012 & 7.70 & $-332 \%$ & $\$$ & 157.40 & $11 \%$ \\
\hline 2013 & 46.80 & $84 \%$ & $\$$ & 168.70 & $7 \%$ \\
\hline 2014 & 15.60 & $-200 \%$ & $\$$ & 149.10 & $-13 \%$ \\
\hline 2015 & 30.00 & $48 \%$ & $\$$ & 140.00 & $-7 \%$ \\
\hline 2016 & 36.30 & $17 \%$ & $\$$ & 129.60 & $-8 \%$ \\
\hline
\end{tabular}

Tabla A5 Principales productos exportados por Honduras a Taiwán 2005-2016 (septiembre)

\begin{tabular}{|c|c|c|c|c|c|c|c|c|c|c|c|c|}
\hline Productos por Clasificacion Arancelaria. & \multicolumn{12}{|c|}{ Años } \\
\hline Código a 2 digitos (Capitulo CAUCA) & 2005 & 2006 & 2007 & 2008 & 2009 & 2010 & 2011 & 2012 & 2013 & 2014 & 2015 & Septiembre 2016 \\
\hline 03 Capitulo 3 - Pescados y crustáceos, moluscos & 0.00 & 0.00 & & 284.31 & 338.51 & $2,678.50$ & $6,079.27$ & $16,439.57$ & $20,351.61$ & $12,519.83$ & $17,402.72$ & $9,080.72$ \\
\hline 72 Capitulo 72 - Fundición, hierro y acero & $2,565.32$ & $1,538.76$ & $5,148.91$ & $19,063.57$ & $4,289.35$ & $18,272.73$ & $12,316.70$ & $4,321.36$ & $2,553.58$ & $2,249.94$ & 807.11 & $1,568.40$ \\
\hline 47 Capitulo 47 - Pasta de madera o de las demás materias & 60.61 & & 10.62 & 0.00 & 88.53 & 225.02 & 416.67 & 385.93 & 421.76 & $1,087.50$ & $2,087.91$ & 931.87 \\
\hline 09 Capitulo 9 - Café, té, yerba mate y especias & 405.34 & 792.79 & 671.66 & $1,070.35$ & $1,233.14$ & $1,413.59$ & 450.91 & $2,213.10$ & $2,175.52$ & $1,847.28$ & $1,670.97$ & 786.26 \\
\hline 17 Capitulo 17 - Azúcares y articulos de confiteria & & 0.00 & 0.00 & & & 0.00 & & $2,377.31$ & $4,359.78$ & $13,580.18$ & 0.00 & 674.80 \\
\hline 76 Capitulo 76 - Aluminio y sus manufacturas & 254.72 & 78.22 & 422.26 & $1,810.97$ & 200.20 & 420.10 & 625.18 & 389.28 & $1,049.47$ & $1,004.63$ & 407.45 & 249.91 \\
\hline 23 Capitulo 23 - Residuos y desperdicios de las industrias & 22.00 & 51.00 & 0.00 & 10.92 & & 43.75 & 203.74 & & 225.43 & 187.20 & 151.06 & 172.64 \\
\hline 84 Capitulo 84 - Reactores nucleares, calderas, máquinas & 72.79 & 5.58 & 60.66 & 35.48 & 1.70 & 1.32 & 176.45 & 21.94 & 29.40 & 20.11 & 2.53 & 10.45 \\
\hline 94 Capitulo 94 - Muebles; mobiliario medicoquirúrgico & 16.95 & 1.46 & 0.00 & 0.00 & 8.14 & 0.92 & 3.35 & 1.26 & 0.81 & 0.00 & 1.93 & 1.21 \\
\hline 24 Capitulo 24 - Tabaco y sucedáneos del tabaco elaborados & 5.54 & 15.38 & 1.90 & & 0.59 & 0.00 & 1.42 & & & & 0.86 & 1.08 \\
\hline 63 Capitulo 63 - Los demás articulos textiles confeccionados & 0.00 & 3.70 & 0.00 & 0.00 & 1.80 & 2.64 & 3.63 & 1.07 & 0.36 & 0.00 & 0.89 & 0.61 \\
\hline 85 Capitulo 85 - Máquinas, aparatos y material eléctrico & 4.08 & 0.28 & 17.21 & 2.11 & 14.05 & 0.29 & 20.52 & 0.86 & 0.14 & 0.10 & 0.29 & 0.42 \\
\hline 69 Capitulo 69 - Productos cerámicos & 0.00 & 0.26 & 0.00 & 0.00 & 0.28 & 0.00 & 0.64 & 0.36 & 0.36 & 0.00 & 0.22 & 0.09 \\
\hline 57 Capitulo 57 - Alfombras y demás revestimientos & 0.00 & 0.16 & 0.00 & 0.00 & 0.12 & 0.00 & 0.25 & 0.05 & 0.46 & 0.00 & 0.09 & 0.06 \\
\hline 70 Capitulo 70 - Vidrio y sus manufacturas & 0.00 & 0.25 & 0.00 & 3.18 & 2.31 & 0.05 & 0.40 & 0.11 & 0.14 & 0.00 & 0.14 & 0.06 \\
\hline 42 Capitulo 42 - Manufacturas de cuero & 0.00 & 0.17 & 0.00 & 0.00 & 0.05 & 0.02 & 0.09 & 0.25 & 0.00 & 0.00 & 0.03 & 0.05 \\
\hline 39 Capitulo 39 - Plástico y sus manufacturas & 11.23 & 0.03 & 35.48 & 25.70 & 14.25 & 0.11 & 184.99 & 0.05 & 9.48 & 96.82 & 15.27 & 0.04 \\
\hline 49 Capitulo 49 - Productos editoriales, de la prensa & 0.00 & 0.13 & 0.00 & 0.00 & 0.10 & 0.27 & 0.18 & 0.18 & 0.46 & 0.00 & 0.04 & 0.03 \\
\hline TOTAL & $3,418.58$ & $2,488.16$ & $6,368.69$ & $22,306.59$ & $6,193.10$ & $23,059.29$ & $20,484.37$ & $26,152.68$ & $31,178.78$ & $32,593.60$ & $22,549.52$ & $13,478.68$ \\
\hline
\end{tabular}

Fuente: Elaboración propia con datos del Sistema de Estadísticas de Comercio Centroamericano SEC-SIECA 
Tabla A6 Principales productos importados de Taiwán por Honduras 2005-2016 (septiembre)

\begin{tabular}{|c|c|c|c|c|c|c|c|c|c|c|c|c|}
\hline Peoductos por clasificacion arancelaria. & \multicolumn{12}{|c|}{ Años } \\
\hline Código a 2 digitos (Capitulo CAUCA) & 2005 & 2006 & 2007 & 2008 & 2009 & 2010 & 2011 & 2012 & 2013 & 2014 & 2015 & Septiembre 2016 \\
\hline 39 Capitulo 39 - Plástico y sus manufacturas & $1,829.16$ & $2,190.74$ & $2,396.37$ & $3,254.88$ & $3,461.97$ & $4,268.34$ & $2,940.45$ & $3,758.21$ & $27,505.03$ & $31,710.12$ & $29,338.31$ & $24,133.38$ \\
\hline 84 Capitulo 84 - Reactores nucleares, calderas & $6,223.99$ & $7,598.62$ & $7,591.84$ & $8,500.75$ & $5,928.41$ & $8,349.57$ & $6,531.06$ & $6,789.28$ & $7,151.39$ & $14,199.58$ & \begin{tabular}{|r|}
$19,099.87$ \\
\end{tabular} & $16,563.63$ \\
\hline 85 Capitulo 85 - Máquinas, aparatos y material eléctrico & $2,821.96$ & $4,156.10$ & $5,972.63$ & $4,707.47$ & $4,386.19$ & $7,923.10$ & $5,448.60$ & $4,738.46$ & $4,905.76$ & $5,468.34$ & $7,839.44$ & $7,986.84$ \\
\hline 40 Capitulo 40 - Caucho y sus manufacturas & $1,550.64$ & $1,326.47$ & $1,536.62$ & $1,294.77$ & $1,160.66$ & $2,182.03$ & $2,952.88$ & $3,746.66$ & $3,229.22$ & $3,494.16$ & $3,985.36$ & $3,000.57$ \\
\hline 22 Capitulo 22 - Bebidas, liquidos alcohólicos y vinagre & 5.19 & 0.00 & 6.81 & 10.52 & 0.22 & 32.20 & 0.00 & 0.06 & 0.00 & $1,429.69$ & $3,211.60$ & $2,828.75$ \\
\hline 73 Capitulo 73 - Manufacturas de fundición, de hierro & 924.48 & 938.08 & $1,669.18$ & $1,423.85$ & $1,226.32$ & $1,383.12$ & 831.32 & $1,127.48$ & $1,368.60$ & $1,065.68$ & $1,882.57$ & $1,823.52$ \\
\hline 55 Capitulo 55 - Fibras sintéticas o artificiales & 377.83 & 156.27 & 64.24 & 140.65 & 113.80 & 91.14 & 61.78 & 49.20 & 57.75 & 0.74 & $1,150.32$ & $1,167.69$ \\
\hline 82 Capitulo 82 - Herramientas y útiles & 84.28 & 85.37 & 161.28 & 206.70 & 79.45 & 329.49 & 119.47 & 134.31 & 91.83 & 358.29 & 708.90 & $1,057.26$ \\
\hline 83 Capitulo 83 - Manufacturas diversas de metal común & 610.61 & 466.29 & 813.25 & $1,191.79$ & 338.05 & $1,252.26$ & $1,256.10$ & $1,262.06$ & $1,057.08$ & $1,140.23$ & $1,268.43$ & $1,003.32$ \\
\hline 90 Capitulo 90 - Instrumentos y aparatos de óptica, fotografia & 276.94 & 695.83 & 263.85 & 279.10 & 316.25 & 608.17 & 247.53 & 220.54 & 176.82 & 498.19 & 928.01 & 871.26 \\
\hline 72 Capitulo 72 - Fundición, hierro y acero & $1,592.95$ & $2,503.08$ & $1,701.70$ & $11,574.98$ & $4,760.99$ & $6,824.97$ & $2,649.16$ & $1,410.62$ & 689.78 & $1,810.42$ & $2,468.01$ & 810.03 \\
\hline 94 Capitulo 94 - Muebles; mobiliario medicoquirúrgico & 289.38 & 139.74 & 633.56 & 354.72 & 208.76 & $1,032.26$ & 421.68 & 363.32 & 430.46 & 524.17 & 705.28 & 536.65 \\
\hline 70 Capitulo 70 - Vidrio y sus manufacturas & 394.27 & 330.99 & 544.07 & 655.22 & 399.38 & 429.82 & 469.61 & 302.43 & 417.91 & 323.02 & 495.62 & 494.50 \\
\hline 35 Capitulo 35 - Materias albuminoideas & 46.95 & 44.07 & 76.65 & 38.76 & 79.16 & 149.07 & 103.45 & 136.67 & 185.46 & 245.79 & 494.91 & 434.58 \\
\hline 95 Capitulo 95 - Juguetes, juegos y articulos para recreo & 722.83 & 260.47 & 560.94 & 327.52 & 184.46 & 579.28 & 415.06 & 109.85 & 307.91 & 235.37 & 306.05 & 384.24 \\
\hline 96 Capitulo 96 - Manufacturas diversas & 159.53 & 69.45 & 416.75 & 218.59 & 198.71 & 355.79 & 198.78 & 416.74 & 274.63 & 253.93 & 491.77 & 336.61 \\
\hline 29 Capitulo 29 - Productos quimicos orgánicos & 0.00 & 0.00 & 91.90 & 157.37 & 13.62 & 13.98 & 35.33 & 0.60 & 58.19 & 66.01 & 360.73 & 329.29 \\
\hline Total & $25,410.55$ & $32,406.86$ & $35,570.76$ & $42,237.80$ & $28,554.70$ & $44,767.47$ & $32,405.71$ & $33,925.13$ & \begin{tabular}{|r|}
$54,795.68$ \\
\end{tabular} & $71,433.70$ & $85,701.20$ & $71,050.23$ \\
\hline
\end{tabular}

Fuente: Elaboración propia con datos del Sistema de Estadísticas de Comercio Centroamericano SEC-SIECA

Tabla A7 Principales productos exportados por El Salvador a Taiwán 2005-2016 (septiembre)

\begin{tabular}{|c|c|c|c|c|c|c|c|c|c|c|c|c|}
\hline Productos por Clasificacion Arancelaria & \multicolumn{12}{|c|}{ Años } \\
\hline Código a 2 digitos (Capitulo) & 2005 & 2006 & 2007 & 2008 & 2009 & 2010 & 2011 & 2012 & 2013 & 2014 & 2015 & Septiembre 2016 \\
\hline 17 Capitulo 17 - Azícares y articulos de confiteria & 794.40 & 0.00 & 0.00 & 0.00 & $11,716.72$ & $3,172.47$ & \begin{tabular}{|l|}
$24,193.56$ \\
\end{tabular} & $2,777.17$ & $38,964.83$ & $10,241.24$ & $24,934.65$ & $26,379.02$ \\
\hline 09 Capitulo 9 - Café, té, yerba mate y especias & 0.00 & 35.89 & 50.74 & 464.07 & 485.10 & 109.67 & 381.32 & 237.67 & $2,709.63$ & $1,653.65$ & $1,542.48$ & $1,955.12$ \\
\hline 47 Capitulo 47 - Pasta de madera papel o cartón & 29.38 & 8.46 & 21.27 & 95.31 & 192.15 & 659.05 & 882.85 & 762.97 & 641.47 & 787.48 & $1,321.78$ & $1,086.23$ \\
\hline 03 Capitulo 3 - Pescados y crustáceos, moluscos & 634.50 & $1,241.74$ & 115.00 & & & & & & 0.00 & 0.00 & 579.89 & 568.17 \\
\hline 72 Capitulo 72 - Fundición, hierro y acero & 398.48 & 335.02 & 606.45 & $6,349.03$ & $1,542.97$ & $8,149.68$ & $5,523.75$ & $1,194.51$ & $1,829.64$ & 433.05 & 571.33 & 458.04 \\
\hline 39 Capitulo 39 - Plástico y sus manufacturas & 0.10 & 109.33 & 2.56 & 0.98 & 17.03 & 135.89 & 203.96 & 254.98 & 184.10 & 311.67 & 420.23 & 338.63 \\
\hline 76 Capitulo 76 - Aluminio y sus manufacturas & $2,654.90$ & $3,419.16$ & \begin{tabular}{|r|r|}
$5,745.88$ \\
\end{tabular} & 672.77 & 0.00 & $1,003.55$ & $1,745.19$ & $1,283.59$ & 788.71 & 626.62 & 369.88 & 254.84 \\
\hline 52 Capitulo 52 - Algodón & 0.00 & 0.06 & 0.00 & 0.00 & 0.00 & 0.00 & 0.00 & 0.00 & 0.00 & 0.00 & 0.00 & 138.01 \\
\hline 61 Capitulo 61 - Prendas y complementos (accesorios) & 0.00 & 0.05 & 0.01 & 0.00 & 15.14 & 0.00 & 0.00 & 32.72 & 24.20 & 70.84 & 48.04 & 81.29 \\
\hline 44 Capitulo 44 - Madera, carbón vegetal & 0.00 & 7.06 & 0.00 & 0.00 & 0.00 & 0.00 & 1.25 & 133.89 & 185.74 & 227.42 & 65.61 & 54.13 \\
\hline 58 Capitulo 58 - Tejidos especiales; superficies textiles & 0.00 & 0.00 & 0.00 & 0.00 & 0.00 & 0.00 & 0.00 & 0.00 & 5.87 & 51.01 & 34.95 & 28.43 \\
\hline 84 Capitulo 84 - Reactores nucleares, calderas & 2.01 & 40.15 & 1.46 & 67.70 & 2.72 & 18.46 & 60.31 & 0.87 & 1.49 & 0.00 & 0.00 & 20.00 \\
\hline 01 Capitulo 1 - Animales vivos & 6.60 & 14.00 & 13.01 & 14.06 & 6.05 & 12.35 & 5.85 & 10.40 & 51.50 & 147.11 & 63.27 & 12.50 \\
\hline 98 Capitulo especifico utilizado por el pais - & 4.50 & 8.00 & 4.00 & 2.94 & 14.80 & 17.53 & 5.62 & 8.92 & 23.03 & 2.00 & 10.79 & 7.91 \\
\hline 06 Capitulo 6 - Plantas vivas y productos de la floricultura & 0.00 & 0.00 & 0.00 & 0.00 & 0.00 & 0.00 & 0.00 & 0.00 & 0.00 & 3.35 & 0.00 & 2.59 \\
\hline TOTAL & $4,524.86$ & $5,218.91$ & $5,560.39$ & $7,666.86$ & $13,992.68$ & $|13,278.63|$ & \begin{tabular}{|l|l|}
$33,003.66$ \\
3
\end{tabular} & $6,697.68$ & $45,410.19$ & $14,555.44$ & $29,962.90$ & $31,384.91$ \\
\hline
\end{tabular}

Fuente: Elaboración propia con datos del Sistema de Estadísticas de Comercio Centroamericano SEC-

SIECA

Tabla A8 Principales productos importados de Taiwán por El Salvador 2005-2016 (septiembre)

\begin{tabular}{|c|c|c|c|c|c|c|c|c|c|c|c|c|}
\hline Productos por Clasificacion Arancelaria & \multicolumn{12}{|c|}{ Años } \\
\hline Código a 2 digitos (Capitulo CAUCA) & 2005 & 2006 & 2007 & 2008 & 2009 & 2010 & 2011 & 2012 & 2013 & 2014 & 2015 & Septiembre 2016 \\
\hline 39 Capitulo 39 - Plástico y sus manufacturas & $19,253.66$ & $22,898.47$ & $25,704.62$ & $47,247.94$ & $38,734.23$ & \begin{tabular}{|l|}
$39,411.36$ \\
\end{tabular} & $77,249.90$ & $88,754.05$ & $86,239.82$ & $70,903.24$ & $59,481.50$ & $44,448.89$ \\
\hline 84 Capitulo 84 - Reactores nucleares, calderas & $8,068.54$ & $10,536.49$ & $20,051.79$ & $13,481.20$ & $7,629.55$ & $11,453.18$ & $13,446.38$ & $16,971.76$ & $19,565.92$ & $17,928.80$ & $16,318.60$ & $10,787.61$ \\
\hline 85 Capitulo 85 - Máquinas, aparatos y material eléctrico & $5,009.23$ & $5,888.02$ & $6,985.00$ & $6,264.02$ & $6,916.56$ & $7,932.41$ & $8,812.24$ & $6,646.28$ & $7,256.55$ & $7,161.11$ & $9,896.31$ & $7,725.67$ \\
\hline 87 Capitulo 87 - Vehiculos automóviles, tractores & $4,769.97$ & $6,258.60$ & $7,422.64$ & $5,555.73$ & $4,067.50$ & $4,484.83$ & $6,128,16$ & $6,943.07$ & $8,199.06$ & $8,619.03$ & $8,303.69$ & $6,661.30$ \\
\hline 40 Capitulo 40 - Caucho y sus manufacturas & $1,594.52$ & $1,906.34$ & $1,643.64$ & $2,113.12$ & $1,775.79$ & $2,370.39$ & $3,465.28$ & $4,085.65$ & $3,875.99$ & $3,732.52$ & $3,616.23$ & $2,321.05$ \\
\hline 73 Capitulo 73 - Manufacturas de fundición, de hierro & $1,860.65$ & $2,669.98$ & $2,380.74$ & $2,509.94$ & $1,785.05$ & $2,336.59$ & $2,063.89$ & $3,275.81$ & $3,092.46$ & $3,361.44$ & $2,976.30$ & $1,882.35$ \\
\hline 94 Capitulo 94 - Muebles; mobiliario medicoquirúrgico & $1,011.75$ & $1,171.10$ & $1,586.34$ & $1,417.57$ & $1,150.87$ & 979.29 & $1,475.24$ & $1,437.18$ & $2,054.46$ & $2,362.07$ & $1,977.28$ & $1,682.61$ \\
\hline 54 Capitulo 54 - Filamentos sintéticos o artificiales & $2,937.18$ & $5,562.30$ & $9,744.73$ & $12,368.83$ & $3,586.16$ & $5,385.73$ & $5,204.01$ & $4,540.40$ & $5,467.10$ & $3,013.11$ & $3,717.28$ & $1,654.07$ \\
\hline 72 Capitulo 72 - Fundición, hierro y acero & $1,184.07$ & $1,445.65$ & $2,438.17$ & $2,821.18$ & $1,307.57$ & $1,621.15$ & $1,519.61$ & $1,947.97$ & $1,693.76$ & $1,488.06$ & $1,544.53$ & $1,377.07$ \\
\hline 96 Capitulo 96 - Manufacturas diversas & 541.92 & 372.06 & 408.14 & 476.34 & 489.82 & 916.59 & $1,391.47$ & $1,374.28$ & $1,254.92$ & $1,416.94$ & $1,592.09$ & $1,287.93$ \\
\hline 32 Capitulo 32 - Extractos curtientes o tintóreos & 372.61 & $1,380.90$ & $1,158.46$ & $1,648.14$ & $2,623.82$ & $2,214.17$ & $2,163.48$ & $2,305.96$ & $2,812.32$ & $3,397.62$ & $1,366.17$ & $1,091.70$ \\
\hline 60 Capitulo 60 - Tejidos de punto & 247.73 & 270.67 & $1,362.07$ & $4,475.33$ & $4,563.72$ & $3,968.48$ & $3,022.88$ & $2,752.00$ & 6.280 .53 & $1,475.43$ & $2,709.16$ & $1,061.47$ \\
\hline 59 Capitulo 59 - Telas impregnadas, recubiertas & $1,371.83$ & $1,359.03$ & $1,592.02$ & $1,525.49$ & 900.28 & 843.31 & $1,271.62$ & $1,268.41$ & $1,459.85$ & $1,102.78$ & $1,424.37$ & 968.56 \\
\hline 49 Capitulo 49 - Productos editoriales, de la prensa & 24.82 & 34.37 & 251.16 & 138.02 & 86.99 & 317.21 & 171.72 & 497.71 & 994.12 & $1,624.75$ & $1,416.17$ & 897.19 \\
\hline 83 Capitulo 83 - Manufacturas diversas de metal común & $1,078.53$ & $1,200.69$ & $1,476.01$ & $1,528.09$ & $1,052.70$ & $1,498.13$ & $1,687.51$ & $1,651.26$ & $1,545.50$ & $1,289.41$ & $1,496.74$ & 892.51 \\
\hline 20 Capitulo 20 - Preparaciones de hortalizas, de frutas & 0.34 & 0.13 & 0.64 & 1.55 & 0.01 & 0.00 & 0.01 & 0.41 & 0.42 & 0.88 & 81.44 & 788.41 \\
\hline 58 Capitulo 58 - Tejidos especiales; superficies textiles & 571.87 & 613.88 & 650.41 & 541.91 & 849.29 & 557.16 & \begin{tabular}{ll|l}
652.68 & \\
\end{tabular} & $1,122.38$ & $1,890.95$ & $1,176.42$ & $1,374.20$ & 505.03 \\
\hline 70 Capitulo 70 - Vidrio y sus manufacturas & 356.18 & 492.93 & 621.01 & 563.77 & 353.30 & 375.08 & 381.37 & 582.06 & 695.07 & 539.88 & 659.38 & 474.37 \\
\hline 68 Capitulo 68 - Manufacturas de piedra, yeso fraguable & 119.39 & 125.21 & 190.87 & 258.35 & 218.79 & 272.27 & 189.02 & 231.30 & 264.80 & 301.84 & 313.26 & 419.90 \\
\hline 82 Capitulo 82 - Herramientas y útiles & 433.93 & 647.74 & 546.66 & 596.94 & 301.98 & 483.02 & 440.39 & 546.09 & 695.21 & 737.99 & 798.94 & 406.86 \\
\hline Total & $50,808.72$ & $64,834.57$ & $86,215.09$ & $105,533.44$ & $78,393.97$ & $87,420.34$ & $130,736.85$ & $146,934.02$ & $155,338.83$ & $131,633.31$ & $121,063.65$ & $87,334.56$ \\
\hline
\end{tabular}

Fuente: Elaboración propia con datos del Sistema de Estadísticas de Comercio Centroamericano SECSIECA 
Tabla A9 Principales productos exportados por Guatemala a Taiwan 2005-2016 (septiembre)

\begin{tabular}{|c|c|c|c|c|c|c|c|c|c|c|c|c|}
\hline Productos por clasificaciona arancelaria. & \multicolumn{12}{|c|}{ Años } \\
\hline Código a 2 digitos (Capitulo) & 2005 & 2006 & 2007 & 2008 & 2009 & 2010 & 2011 & 2012 & 2013 & 2014 & 2015 & Septiembre 2016 \\
\hline 17 Capitulo 17 - Azúcares y articulos de confiteria & $11,818.28$ & $10,869.15$ & $14,494.74$ & $7,198.65$ & \begin{tabular}{|l|l|}
$522,713.93$ \\
\end{tabular} & $33,459.92$ & $28,296.14$ & \begin{tabular}{l|l|}
$47,198.78$ \\
\end{tabular} & \begin{tabular}{|l|l|}
$86,538.22$ \\
\end{tabular} & $51,136.97$ & \begin{tabular}{l|l|}
7 & $29,755.50$ \\
\end{tabular} & $60,146.05$ \\
\hline 09 Capitulo 9 - Café, té, yerba mate y especias & 201.79 & $1,683.63$ & $3,048.76$ & $4,558.96$ & \begin{tabular}{|r|}
6 \\
6
\end{tabular} & $5,873.80$ & $4,483.78$ & \begin{tabular}{l|l|}
$8,413.28$ \\
\end{tabular} & $7,069.71$ & $5,852.70$ & $8,976.42$ & $8,162.13$ \\
\hline 47 Capitulo 47 - Pasta de madera & & & & 52.90 & 164.50 & 359.19 & 532.47 & 391.22 & 209.78 & 842.53 & $2,040.73$ & $2,094.99$ \\
\hline 72 Capitulo 72 - Fundición, hierro y acero & 206.96 & 0.00 & 57.40 & $3,942.54$ & 606.62 & \begin{tabular}{|r|}
$1,936.94$ \\
\end{tabular} & $1,230.52$ & 300.11 & 377.39 & 239.68 & 168.55 & 309.37 \\
\hline 08 Capitulo 8 - Frutas y frutos comestibles & & & 0.01 & & 0.02 & & 93.00 & 215.97 & 127.50 & 500.40 & 512.45 & 300.21 \\
\hline 74 Capitulo 74 - Cobre y sus manufacturas & 0.00 & 0.00 & 0.03 & 286.21 & 53.78 & 0.00 & 0.00 & 62.75 & 0.00 & 12.00 & 312.72 & 244.92 \\
\hline 76 Capitulo 76 - Aluminio y sus manufacturas & 70.16 & 21.25 & 952.73 & $1,573.43$ & 428.55 & 238.21 & 308.90 & 300.49 & 266.88 & 167.91 & 86.92 & 91.07 \\
\hline 48 Capitulo 48 - Papel y cartón; manufacturas & 0.00 & 0.00 & 0.05 & 0.00 & 0.00 & 0.00 & 0.00 & 0.00 & 0.00 & 1.76 & 0.00 & 66.93 \\
\hline 40 Capitulo 40 - Caucho y sus manufacturas & 0.00 & 0.00 & 0.00 & 0.00 & 0.00 & 0.00 & 0.00 & 0.00 & 0.00 & 20.61 & 0.00 & 61.20 \\
\hline 44 Capitulo 44 - Madera, carbón vegetal y manufacturas de & 25.12 & 116.84 & 209.70 & 198.66 & 245.82 & 298.71 & 482.04 & 164.85 & 136.03 & 41.49 & 2.50 & 51.61 \\
\hline 71 Capitulo 71 - Perlas finas (naturales) o cultivadas & 0.00 & 0.00 & 0.00 & 0.00 & 0.04 & 0.30 & 0.65 & 1.94 & 5.31 & 175.44 & 73.09 & 34.82 \\
\hline 06 Capitulo 6 - Plantas vivas & 1.52 & 2.59 & 5.86 & 2.03 & 2.11 & 5.43 & 8.99 & 13.67 & 16.73 & 26.31 & 33.74 & 33.99 \\
\hline 79 Capitulo 79 - Cinc y sus manufacturas & 0.00 & 0.00 & 1.15 & 315.66 & 321.87 & 35.50 & 97.25 & 60.95 & 112.40 & 127.60 & 33.24 & 28.62 \\
\hline 25 Capitulo 25 - Sal; azufre; tierras y piedras; yesos, & 0.00 & 0.00 & 0.90 & 34.78 & 20.00 & 9.50 & 165.96 & 29.61 & 3.28 & 14.46 & 10.45 & 21.20 \\
\hline 39 Capitulo 39 - Plástico y sus manufacturas & 0.00 & 0.00 & 9.93 & 5.11 & 11.40 & 62.54 & 79.99 & 1.46 & 110.11 & 46.30 & 101.05 & 20.33 \\
\hline 61 Capitulo 61 - Prendas y complementos (accesorios) & 0.00 & 0.00 & 0.00 & 0.00 & 0.00 & 0.12 & 0.00 & 0.00 & 0.00 & 3.25 & 7.53 & 12.91 \\
\hline 33 Capitulo 33 - Aceites esenciales y resinoides & 0.00 & 0.06 & 0.00 & 0.00 & 0.00 & 0.10 & 0.00 & 2.42 & 5.16 & 13.38 & 4.38 & 7.86 \\
\hline 85 Capitulo 85 - Máquinas, aparatos y material eléctrico & 2.96 & 82.75 & 70.42 & 172.82 & 3.28 & 27.74 & 1.29 & 0.21 & 1.51 & 6.23 & 0.40 & 4.07 \\
\hline 20 Capitulo 20 - Preparaciones de hortalizas & 0.00 & 0.00 & 0.00 & 0.06 & 0.00 & 0.00 & 0.00 & 0.00 & 0.00 & 0.00 & 0.00 & 3.81 \\
\hline 84 Capitulo 84 - Reactores nucleares, calderas, máquinas & 1.77 & 2.83 & 5.69 & 13.89 & 19.30 & 9.51 & 1.91 & 28.01 & 87.27 & 0.45 & 0.21 & 3.26 \\
\hline 94 Capitulo 94 - Muebles; mobiliario medicoquirúrgico & 5.44 & 6.76 & 3.88 & 1.09 & 2.31 & 1.12 & 1.79 & 0.90 & 1.07 & 1.26 & 0.47 & 1.50 \\
\hline Total & $12,333.99$ & $12,785.86$ & $18,861.24$ & $18,356.78$ & \begin{tabular}{|l|l|}
$26,147.48$ \\
\end{tabular} & $42,318.62$ & $35,784.69$ & \begin{tabular}{|c|c|}
$96,186.61$ \\
9
\end{tabular} & $55,068.35$ & $59,229.45$ & \begin{tabular}{|l|l|}
5 & $42,120.33$ \\
\end{tabular} & $71,700.84$ \\
\hline
\end{tabular}

Fuente: Elaboración propia con datos del Sistema de Estadísticas de Comercio Centroamericano SEC-SIECA

Tabla A10 Principales productos importados de Taiwan por Gatemala 2005-2016 (septiembre)

\begin{tabular}{|c|c|c|c|c|c|c|c|c|c|c|c|c|}
\hline Productos por clasificacion arancelaria. & \multicolumn{12}{|c|}{ Años } \\
\hline Código a 2 digitos (Capitulo) & 2005 & 2006 & 2007 & 2008 & 2009 & 2010 & 2011 & 2012 & 2013 & 2014 & 2015 & Septiembre 2016 \\
\hline 39 Capitulo 39 - Plástico y sus manufacturas & $7,973.56$ & $8,519.25$ & $6,249.81$ & $10,462.40$ & $9,065.99$ & $8,043.62$ & $19,152.02$ & $18,524.76$ & $22,885.78$ & $20,195.70$ & $21,436.29$ & $17,476.63$ \\
\hline 84 Capitulo 84 - Reactores nucleares, calderas & $10,508.17$ & $10,766.67$ & $13,391.13$ & $12,164.30$ & $10,377.75$ & $12,424.23$ & $14,115.80$ & $14,017.93$ & $12,981.52$ & $11,853.48$ & $13,939.61$ & $17,112.05$ \\
\hline 87 Capitulo 87 - Vehículos automóviles, tractores & $21,087.76$ & $16,812.29$ & $15,767.34$ & $15,923.80$ & $10,327.36$ & $12,025.32$ & $12,729.83$ & $10,473.85$ & $9,774.74$ & $10,118.78$ & $14,445.86$ & $16,366.99$ \\
\hline 85 Capitulo 85 - Máquinas, aparatos y material eléctrico & $9,893.60$ & $10,956.09$ & $10,705.22$ & $10,828.57$ & $10,991.66$ & $12,203.47$ & $14,720.00$ & $12,974.74$ & $10,944.94$ & $9,494.58$ & $13,811.18$ & $13,768.62$ \\
\hline 72 Capitulo 72 - Fundición, hierro y acero & 550.20 & 770.27 & $4,011.08$ & $2,052.99$ & $1,434.54$ & $1,421.59$ & $2,314.37$ & $2,759.11$ & $2,737.93$ & 182.58 & $3,149.99$ & $3,296.54$ \\
\hline 40 Capitulo 40 - Caucho y sus manufacturas & $3,360.50$ & $2,590.45$ & $3,764.96$ & $4,076.77$ & $3,036.27$ & $3,988.72$ & $5,440.26$ & $5,408.51$ & $4,156.85$ & 627.39 & 41.42 & 94.24 \\
\hline 73 Capitulo 73 - Manufacturas de fundición, de hierro & $2,589.79$ & $2,290.49$ & $2,543.36$ & $3,626.15$ & $2,280.75$ & $1,927.03$ & $2,767.95$ & $2,564.72$ & $2,165.03$ & $2,547.49$ & $2,898.73$ & 608.62 \\
\hline 95 Capitulo 95 - Juguetes, juegos y articulos para recreo & $1,965.31$ & $1,694.58$ & $1,711.12$ & $1,134.99$ & 784.06 & $1,499.29$ & $1,219.25$ & $1,490.54$ & $1,498.88$ & $1,791.86$ & $1,944.57$ & $2,508.32$ \\
\hline 38 Capitulo 38 - Productos de las industrias quimicas & 419.92 & 90.22 & 104.11 & 580.60 & $2,963.21$ & $1,049.20$ & 247.29 & $2,871.39$ & $3,453.08$ & $6,790.45$ & $5,796.49$ & $2,219.31$ \\
\hline 94 Capitulo 94 - Muebles; mobiliario medicoquirúrgico & $2,367.89$ & $2,446.23$ & $2,151.54$ & $1,965.22$ & $1,357.46$ & $1,760.40$ & $2,227.60$ & $2,306.83$ & $2,424.11$ & $2,620.78$ & $2,004.19$ & $2,127.96$ \\
\hline 35 Capitulo 35 - Materias albuminoideas & 390.29 & 478.59 & 761.56 & $1,087.96$ & $1,140.03$ & $1,334.47$ & $1,210.27$ & $1,025.33$ & 961.44 & $1,300.90$ & $1,169.69$ & $1,565.26$ \\
\hline 54 Capitulo 54 - Filamentos s & $2,535.18$ & $1,896.90$ & $1,770.33$ & $2,670.89$ & $1,154.53$ & $1,431.28$ & $1,346.27$ & $1,270.16$ & $1,208.61$ & 587.42 & 299.95 & 09.02 \\
\hline 90 Capitulo 90 - Instrumentos y & $1,317.66$ & 732.69 & $1,140.29$ & $1,978.58$ & 888.32 & $1,164.06$ & $1,360.79$ & 910.06 & 935.33 & $1,003.85$ & $1,618.34$ & 95.24 \\
\hline 82 Capitulo 82 - Herramientas y útiles, articulos de cuchilleria & 499.74 & 532.39 & 508.51 & 524.38 & 466.09 & 364.18 & 670.08 & 842.71 & 470.54 & 927.14 & 31.28 & $1,308.26$ \\
\hline 83 Capitulo 83 - Manufacturas diversas de metal común & $3,186.28$ & $2,631.21$ & $2,787.59$ & $1,491.11$ & 781.62 & $1,399.50$ & $2,111.17$ & $1,024.59$ & 871.09 & $1,252.65$ & $1,341.68$ & $1,086.90$ \\
\hline 70 Capitulo 70 - Vidrio y sus manufacturas & $1,289.04$ & $1,808.29$ & $1,477.45$ & $1,203.98$ & 905.97 & 852.91 & 952.18 & 827.57 & 717.76 & 613.64 & 778.41 & 935.89 \\
\hline 32 Capitulo 32 - Extractos curtientes o tintóreos & 973.02 & 640.84 & 627.46 & 589.52 & 316.37 & 503.78 & 913.31 & 838.88 & 738.66 & 617.43 & 924.25 & 877.42 \\
\hline 48 Capitulo 48 - Papel y cartón; manufacturas & 709.09 & 772.54 & 889.34 & 850.71 & 544.55 & 934.79 & 968.59 & 758.18 & 902.30 & 881.20 & 670.76 & 775.38 \\
\hline 55 Capitulo 55 - Fibras sintéticas o artificiales & 662.46 & 844.23 & 556.74 & 232.39 & 377.69 & 746.33 & 236.36 & 764.75 & 686.16 & 586.40 & 609.79 & 600.02 \\
\hline Total & $72,279.45$ & $67,274.21$ & $70,918.94$ & $73,445.31$ & $59,194.23$ & $65,074.16$ & $84,703.39$ & $81,654.60$ & $80,514.74$ & $80,993.70$ & $93,212.47$ & $90,732.65$ \\
\hline
\end{tabular}

Fuente: Elaboración propia con datos del Sistema de Estadísticas de Comercio Centroamericano SEC-SIECA 
Tabla A11 Honduras: principales socios comerciales por valor de exportaciones 2016 (US\$ Millones)

\begin{tabular}{|c|c|c|}
\hline Pais & \multicolumn{2}{|c|}{ Exportaciones } \\
\hline Estados Unidos & $S$ & $1,455.80$ \\
\hline E1 Salvador & S & 334.90 \\
\hline Alemania & S & 314.60 \\
\hline Holanda & $S$ & 251.20 \\
\hline Guatemala & $S$ & 236.10 \\
\hline Nicaragua & S & 219.10 \\
\hline Mexico & $S$ & 112.50 \\
\hline Costa Rica & S & 105.30 \\
\hline Belgica & $S$ & 93.50 \\
\hline Taiwán & S & 27.40 \\
\hline Resto de los paises & $S$ & 707.30 \\
\hline
\end{tabular}

Tabla A12 El Salvador: principales socios comerciales por valor de exportaciones 2016 (US\$ Millones)

\begin{tabular}{|l|lr|}
\hline Pais & Exportaciones \\
\hline Estados Unidos & S & $2,557.10$ \\
\hline Guatemala & S & 718.50 \\
\hline Honduras & S & 754.20 \\
\hline Nicaragua & S & 347.00 \\
\hline Costa Rica & S & 247.70 \\
\hline Panamá & S & 125.00 \\
\hline República Dominicana & $\mathrm{S}$ & 81.70 \\
\hline México & $\mathrm{S}$ & 68.10 \\
\hline España & $\mathrm{S}$ & 30.40 \\
\hline Taiwán & $\mathrm{S}$ & 36.30 \\
\hline Resto de los paises & $\mathrm{S}$ & 359.30 \\
\hline Fuente: Elaboración propia con datos \\
Reserva
\end{tabular}


Tabla A13 Guatemala: principales socios comerciales por valor de exportaciones (US\$ Millones)

\begin{tabular}{|l|lr|}
\hline Pais & Exportaciones & \\
\hline Estados Unidos & S & $3,463.70$ \\
\hline El salvador & S & $1,204.30$ \\
\hline Honduras & S & 913.80 \\
\hline Nicaragua & S & 569.10 \\
\hline México & S & 458.60 \\
\hline Costa Rica & S & 425.70 \\
\hline Canada & S & 348.20 \\
\hline Paises Bajos & S & 307.90 \\
\hline Panamá & S & 248.70 \\
\hline Taiwán & S & 73.90 \\
\hline Resto de los paises & S & $2,448.60$ \\
\hline Fuente: Elaboración propia con datos de Banco de Guatemala
\end{tabular}

Fuente: Elaboración propia con datos de Banco de Guatemala 